\title{
Die Elektrizitätsleitung in Krystallen bei hohen Temperaturen
}

von

\author{
C. Doelter, \\ k. M. k. Akad. \\ (Mit 18 Textiguren.)
}

(Vorgelegt in der Sitzung am 20. Jänner 1910.)

Die vorliegende Arbeit bildet die Fortsetzung meiner früheren, im 117. Bande dieser Sitzungsberichte veröffentlichten Untersuchung über die Leitfähigkeit fester Silikate. Die Messungen wurden von Herrn Dr. K. Herold und mir gemeinsam ausgeführt, die Berechnungen sind von Dr. Herold durchgeführt worden; ich danke dem Genannten hiermit für seine Mitarbeit.

In meinen früheren Arbeiten ging ich von der Idee aus, die Dissoziation auch in den Silikatschmelzen nachzuweisen, nachdem ja durch andere Arbeiten, wie die von R. Lorenz u. a. die Elektrolyse ${ }^{1}$ der Salze und Schmelzflüsse nachgewiesen war. Daß elektrolytische Dissoziation auch in Silikatschmelzen stattfindet, dürfte nunmehr feststehen, wie denn auch Elektrolyse der Silikate durchführbar ist.

Eine weitere Frage ist jedoch die der elektrolytischen Leitfähigkeit der festen Silikate, die ich in meiner zweiten Abhandlung ${ }^{2}$ behandelte; insbesondere ist zu entscheiden, ob in Krystallen überhaupt auch elektrolytische Leitfähigkeit möglich ist, und es mußte daher der Kreis der Untersuchung auch auf

1 Literatur siehe bei R. Lorenz, Elektrolyse geschmolzener Salze. Halle 1905, III.

2 Sitzungsber. der Wiener Akad, 117, I (1908), und Zeitschrift für Elektrochemie, 14, Nr. 35 (1908). 
andere Stoffe, insbesondere auf Oxyde ausgedehnt werden. Es handelt sich dabei insbesondere um den Verlauf der Temperaturleitfähigkeitskurve bei hohen Temperaturen und um andere Versuche zur Entscheidung der Frage, ob in Krystallen metallische, d. i. Elektronenleitung oder elektrolytische, d. h. also Ionenleitung vorkommt und wie sich die verschiedenen Stoffe in dieser Hinsicht verhalten.

Bei der Entscheidung spielt die Polarisation eine große Rolle und wurde das Augenmerk daher besonders auf die Messung des Polarisationsstromes gerichtet.

Es wurde aber, wie erwähnt, der Kreis der Versuche auch dahin erweitert, daß nicht nur Silikate, sondern andere Salze, wie Wolframit, Baryt, also wolframsaure und schwefelsaure Salze, untersucht wurden, dann auch Oxyde, wie Zinnstein, Saphir, Rutil und Magneteisen, also metallische Körper.

Seit meiner letzten Publikation erschien ein sehr interessanter Aufsatz von J. Königsberger ${ }^{1}$ über Elektrizitätsleitung in festen Körpern, auf den ich später zurückkomme.

Ich muß aber auf einige der früheren Arbeiten vorerst eingehen.

Die Ansicht, daß auch im festen Zustand elektrolytische Leitfähigkeit, wenigstens in Salzen und vielen Oxyden, vorhanden sei, dürfte die ältere sein. Am ehesten scheint dies auch für Glas und Porzellan bei höheren Temperaturen durchgedrungen zu sein (abgesehen davon auch bei vielen Salzen). Die Literatur kann hier nicht ausführlich erörtert werden, doch mag auf die Arbeiten von Braun, Graetz, Foussereau, L. Poincarré und Bouty, Warburg hingewiesen werden, sowie auf die neueren, besonders wichtigen von R. Lorenz.

\section{Metallisch leitende Krystalle und elektrolytisch leitende.}

Daß die metallischen Krystalle, zumeist Erze, die undurchsichtig sind, meist auch hohes spezifisches Gewicht haben, sich anders verhalten wie die hellen, durchsichtigen, spezifisch leichteren Salze und Oxyde, war vorauszusehen. Doch waren auch Fälle bekannt, daß metallische Mineralien

1 Zeitschrift für Elektrochemie, 15, 97 (1909). 
elektrolytisch leiten; es hängt dies aber mit dem Vorkommen von Einschlüssen zusammen und sind solche Körper keine wirklichen Elektrolyte, sondern Pseudoelektrolyte, da ihre Leitfähigkeit hervorgerufen wird durch in ihnen enthaltene Einscblüsse fremder Flüssigkeiten, die aber dem betreffenden reinen Stoff nicht zukommen. So zeigte Warburg, daß die Leitfähigkeit von Quarzplatten in der Richtung der optischen Achse durch beigemengtes Natriumsilikat verursacht wird; es dürfte die Ansicht, daß hier feinste Kanäle im Quarz parallel seiner Achse vorhanden sind, richtig sein, ${ }^{2}$ es ist ja schon die Ansicht von der Faserstruktur des Quarzes ausgesprochen worden (Michel-Lévy).

Daß bei niederen Temperaturen metallisch leitende Körper durch Wassergehalt, durch Einschlüsse von Lösungen auch elektrolytisch leiten, also »Pseudoelektrolyte « sind, hat O. Weige $1^{3}$ nachgewiesen. Andrerseits ist es möglich, daß bei Sulfiden feste Lösungen von Metall im Sulfid vorliegen; allerdings müßte sich ein solcher Metallgehalt bei der Analyse als Überschuß zeigen. Solche Überschüsse des Metalls gegenüber der Sulfidformel kennen wir, es sind aber wohl mehr Ausnahmsfälle. Bei dem Mineral Magnetkies kommt im Gegensatz dazu ein Überschuß von Schwefel vor. Jedenfalls können Einschlüsse die Leitfähigkeit in verschiedenem Sinne beeinflussen, und zwar sowohl bei metallischen Leitern als auch bei Elektrolyten. Bei ersteren wird sich die durch Beimengung von Elektrolyten verursachte Leitfähigkeit zumeist bei weniger hohen Temperaturen bemerkbar machen; bei hoher Temperatur zeigt sich dann die eigene Leitfähigkeit.

Bei Oxysalzen ist elektrolytische Leitung nicht nur im schmelzflüssigen, sondern auch im festen Zustand zu erwarten.

R. Lorenz hat als erster bei der Elektrolyse vieler geschmolzener Salze wie Zinkchlorid, Zinkbromid, Bleichlorid, Silberchlorid u. a. auch die Polarisation unter dem Schmelz-

1 Ann. der Physik, 32 (1887); 35 (1888); 41 (1890).

2 Nach Beckenkamp, P. Curie und J. Königsberger.

3 So haben viele Körper, z. B. Bleiglanz, Schwefel, poröse Struktur. N. Jahrb. für Min. etc. Beilage-Bd. 21, 325 (1906). 
punkt bestimmt und auch im festen Zustand nachgewiesen.

Es lassen sich Wanderungserscheinungen der Ionen in festen und geschmolzenen Elektrolyten sowie Überführungserscheinungen an Mischungen beobachten. ${ }^{1}$ Lorenz spricht auf Grund seiner Versuche die Meinung aus, daß das Leitvermögen zahlreicher chemischer Verbindungen und Schmelzflüsse im erhitzten festen Zustand ein elektrolytisches sei, das mit Auftreten von Polarisationsspannungen an den Elektroden verknüpft ist. ${ }^{2}$

Galvanische Elemente können nach R. Lorenz außer mit geschmolzenen Elektrolyten auch mit festen aufgebaut werden. R. Lorenz schließt aus seinen Versuchen und dem vorhandenen Material, daß ebenso wie im schmelzflüssigen auch im festen Zustand die Existenz von Ionen anzunehmen ist. Er ist der Ansicht, daß sich sowohl im festen wie im schmelzflüssigen Zustand elektrolytische Dissoziation feststellen läßt bei allen Substanzen, die durch Schmelzen oder Auflösen in einem Lösungsmittel zu Elektrolyten werden.

Die Schmelzung bewirkt nichts anderes als eine Änderung der Ionen beweglichkeit.

Nernst ${ }^{3}$ hat Stäbchen von Oxyden bei hoher Temperatur untersucht und bei solchen großes Leitvermögen konstatiert; er weist den Gedanken ab, daß man es hier mit metallischer Leitfähigkeit zu tun habe, auch mit bezug auf die Lichtabsorption. Auch geben Magnesiastifte, die durch Gleichstrom im.Glühen erhalten werden, polare Unterschiede an den beiden Elektroden. Die Kathode ist immer sehr viel dunkler als die Anode. Nernst und Bose ${ }^{4}$ erklären den Strom, welcher die Stifte dauernd glühend erhält, als sogenannten Reststrom; es läge hier also nur scheinbare metallische Leitfähigkeit vor.

Anders verhält sich eine andere Klasse von Stoffen, die Schwefelverbindungen. Daß eine große Anzahl von Sulfiden metallische Leitung besitzt, scheint durch die bisherigen

1 R. Lorenz, l. c., III, 290.

2 Ebenda, II, 175.

3 Zeitschrift für Elektrochemie, VI, 41 (1899).

4 Ann. d. Phys., 9, 164 (1902). 
Arbeiten genügend bewiesen und auch solche Oxyde, die schon bei gewöhnlicher Temperatur leiten, sind gewiß metallische Leiter; solche Körper hat der Mineraloge schon längst als Erze von den anderen Oxyden ausgeschieden, z. B. $\mathrm{CuO}$, $\mathrm{Cu}_{2} \mathrm{O}, \mathrm{FeO}, \mathrm{Fe}_{2} \mathrm{O}_{3}, \mathrm{PbO}_{2}$, und bei ihnen ist ein metallisches Verhalten erklärlich.

Mit diesen dürfen jedoch die Oxyde $\mathrm{MgO}, \mathrm{SnO}_{2}, \mathrm{SiO}_{2}$, $\mathrm{TiO}_{2}, \mathrm{Al}_{2} \mathrm{O}_{3}, \mathrm{Sb}_{2} \mathrm{O}_{3}$ nicht zusammengeworfen werden. Bei diesen muß das Experiment entscheiden. Da nun Elektrolyse sich nicht gut direkt nachweisen läßt, so bleibt außer der Temperaturkurve nur die Bestimmung der Polarisation zur Entscheidung übrig. Auch bei den früher genannten Oxyden und auch bei Sulfiden wäre es a priori nicht ausgeschlossen, daß bei höheren Temperaturen immerhin auch daneben noch Ionenleitung möglich wäre, wenn auch für diese experimentell kein Beweis vorhanden ist.

Die Versuche von H. Reynolds ${ }^{1}$ mit Zirkonoxyd, das mit anderen Oxyden, Kieselsäureanhydrid, Titandioxyd u. a. gemengt war, sprechen wohl für elektrolytische Leitung.

Wichtig sind die Untersuchungen von F. Horton $;^{2}$ es sind Platten von geschmolzenen Oxyden untersucht worden, $\mathrm{CaO}$, $\mathrm{HgO}, \mathrm{PbO}, \mathrm{Bi}_{2} \mathrm{O}_{3}, \mathrm{CuO}, \mathrm{Na}_{2} \mathrm{O}$, zwischen $0^{\circ}$ und $1300^{\circ}$, auch von Quarzglas, erhalten durch Umschmelzung von Quarz. (Der Autor nimmt irrtümlich an, daß es sich hier um Quarz handle, was nicht der Fall ist, da ja geschmolzener Quarz glasig erstarrt.) Auch bei den übrigen ist es nicht sicher, ob Krystalle oder zum Teil ein Gemenge von solchen mit Glasresten vorlag, doch dürften meinen Erfahrungen nach $\mathrm{CuO}, \mathrm{MgO}, \mathrm{PbO}$, $\mathrm{Bi}_{2} \mathrm{O}_{3}$ ganz krystallin erstarren.

$\mathrm{Daß}$ einzelne dieser Körper eine metallische Leitung zeigten, wie $\mathrm{PbO}, \mathrm{CuO}, \mathrm{Bi}_{2} \mathrm{O}_{3}$, war zu erwarten, während dies bei anderen Stoffen zweifelhaft ist.

Merkmale der elektrolytischen Leitung. Die Frage, ob im festen Zustand elektrolytische Leitung möglich ist, wurde verschieden beantwortet. Auf der Versammlung der Bunsen-

1 Inảuguraldissertation, Göttingen 1902.

2 Phil. Magaz., 11, 505 (1906). 
Gesellschaft in Wien ergab die anläßlich meines Vortrages stattgehabte Diskussion, ${ }^{1}$ daß die meisten der Anwesenden diese Frage im bejahenden Sinne beantworteten.

Doch ist auch die Ansicht aufgetaucht und sie wurde von Königsberger vertreten, daß im festen Zustande meistens nur Elektronenleitung möglich sei.

Es handelt sich also um die Frage, ob in festen krystallisierten Körpern überhaupt elektrolytische Leitfähigkeit möglich ist und zu welcher chemisch definierten Klasse so leitende Krystalle gehören. J. Königsberger ${ }^{2}$ hat nun die Merkmale der elektrolytischen Leitfähigkeit gegenüber der Elektronenleitung zusammengestellt; er unterscheidet fünf Punkte, welche die Feststellung ermöglichen, nämlich außer der Temperaturkurve, die Polarisation bei Ionenleitung, das Vorkommen eines Minimums in der Temperaturkurve bei metallischer Leitung, das Auftreten kontinuierlicher Absorption und Emission bei Elektronenleitung und das allerdings für sehr viele Körper nicht in Betracht kommende Verhalten in wässerigen Lösungen.

J. Königsberger ${ }^{3}$ scheint 1907 noch der Ansicht gewesen zu sein, daß alle festen Körper, und zwar selbst auch Salze keine wirkliche, sondern nur sekundäre elektrolytische Leitfähigkeit zeigen, und er erklärt auch die Elektrolyse des festen Jodsilbers, die O. Lehmann und auch O. Kohlrausch beobachteten, für eine sekundäre. Doch gibt er (p. 192) zu, daß bei krystallisierten Salzen ein wenn auch rascher, so doch kontinuierlicher Übergang von der Elektronenleitung zur eleixtrolytischen Leitung stattfindet. Seine Ansicht dürfte aber für Jodsilber kaum richtig sein und hat er selbst auch ${ }^{4}$ zugegeben, daß in manchen Salzen elektrolytische Dissoziation möglich ist, daher aus dieser Eigenschaft keine Charakteristik zwischen flüssigem und festem Zustand resultiert. Ich halte es für wahrscheinlich, daß die Eigenschaften der Elektronenleitung

1 Zeitschrift für Elektrochemie, 14, N. 35 (1908).

2 Zeitschrift für Elektrochemie, 15, 97 (1909).

3 Jahrb. für Radioaktivität und Elektronik, 4, 158 (1907).

4 Zeitschrift für Elektrochemie, 15, 99 (1909). 
im wesentlichen nur den Metallen und den metallischen Körpern (Erzen), wie den Sulfiden, Metalloxyden, z. B. $\mathrm{Fe}_{2} \mathrm{O}_{3}, \mathrm{Cu}_{2} \mathrm{O}$, $\mathrm{PbO}$, zukommt. Bei Quarz, bei welchem bei Temperaturen über $1300^{\circ}$ die Widerstandskurve sehr flach ist, läßt sich die Frage schwer entscheiden.

Endlich muß einer sehr interessanten Arbeit von R. v. HaBlinger ${ }^{1}$ gedacht werden, in welcher der Beweis. zu führen gesucht wird, daß in vielen Körpern neben metallischer Leitung elektrolytische Leitfähigkeit vorkommt und daß auch in Metallen bei höheren Temperaturen Ionen vorhanden sind. Untersucht wurden insbesondere $\mathrm{Ag}_{2} \mathrm{~S}, \mathrm{Cu}_{2} \mathrm{~S}$, Eisenoxyduloxyd und Schwefel. Seine Ansicht ist also der Königsberger's völlig entgegengesetzt.

Wir kommen nun zu den entscheidenden Merkmalen der elektrolytischen Leitfähigkeit gegenüber der metallischen.

Bei der Unterscheidung zwischen elektrolytischer und metallischer Leitung oder, wie man auch sagen kann, Ionenund Elektronenleitung scheint die Gegenwart ersterer durch Steigen der Leitfähigkeit mit der Temperatur nicht genügend begründet, wie es wohl früher angenommen wurde. Es muß entweder Transport von Masse und Abscheidung durch Elektrofyse konstatiert werden oder Polarisation.

J. Königsberger führt noch als Kriterium der Unterscheidung das Verhalten in wässeriger Lösung gemäß dem Nernst'schen Verteilungssatze an. Verbindungen, die viele Ionen in wässeriger Lösung geben, ohne chemisch zersetzt zu werden, leiten auch im festen Zustand elektrolytisch, dagegen werden die in Wasser unlöslichen oder nur kolloidlöslichen Körper metallische Leiter sein; indessen möchte ich gerade das in Wasser unlösliche Bariumsulfat, das selbst von Königsberger als elektrolytisch leitender Körper bezeichnet wird, anführen.

Dieses Merkmal ist dann, wenn keine in Wasser lösliche Verbindung vorliegt, also bei den meisten Mineralien, nicht anwendbar. Wenn es auch richtig ist, daß in Wasser lösliche Stoffe, wie die Chloride und Jodide, gut elektrolytisch leiten, so ist das Gegenteil, daß in Wasser unlösliche Stoffe nicht

1 Sitzungsber. der Wiener Akad., 115, 1521 (1906). 
elektrolytisch leiten, nicht bewiesen. Wichtig ist meiner Ansicht nach die elektrolytische Leitung oberhalb des Schmelzpunktes und das Verhalten in der Nähe desselben.

Königsberger bespricht auch die Frage, ob man ohne Leitfähigkeitsmessungen die Frage nach Elektronenleitung oder Ionenleitung entscheiden kann. Naheliegend ist es und ja durch frühere Arbeiten von Lorenz u. a. bewiesen, daß ausgesprochene Salze Ionenleitung haben, wovon aber, wie auch aus den bisherigen Versuchen hervorgeht, die Salze der Schwefelwasserstoffsäure wenigstens bei niederen Temperaturen zum Teil eine Ausnahme machen. Diese Säure ist ja eine sehr schwache, alle die betreffenden Verbindungen sind ja auch metallähnliche undurchsichtige Körper, mit Ausnahme einiger, wie $\mathrm{BaS}, \mathrm{K}_{2} \mathrm{~S}, \mathrm{Na}_{2} \mathrm{~S}$, bei welchen elektrolytische Leitfähigkeit wenigstens denkbar ist.

Daß eine Anzahl metallischer Mineralien, wie viele Sulfide, auch Oxyde, schon bei niederen Temperaturen metallische Leitung zeigt, dürfte wohl durch die Arbeiten von Hittorf, Streintz, Weigel, Bädecker, Königsberger u. a. erwiesen sein. Jedoch haben die meisten dieser Forscher bei mäßig erhöhter oder nur bei Zimmertemperatur gemessen. Es ist immerhin denkbar, daß bei hohen Temperaturen (soweit überhaupt ein Arbeiten mit solchen möglich ist, da ja Sulfide sich dann zersetzen) neben der metallischen Leitung auch elektrolytische auftritt; darüber geben jene Arbeiten keinen ganz sicheren Aufschluß, nach der Untersuchung von Haßlinger wäre letzteres der Fall, seine Ansicht ist jedoch nicht genügend gestützt.

Ferner sind von Königsberger, ${ }^{1}$ zum Teil von ihm allein, zum Teil im Vereine mit Reichenhein und K. Schilling, an einigen Oxyden und Sulfiden Messungen vorgenommen worden, nachdem bereits Bäckstro ${ }^{2}$ am Eisenglanz in verschiedenen Richtungen solche ausgeführt hatte. Seine Untersuchungen betreffen zumeist Körper, bei welchen metallische Leitfähigkeit $\mathrm{zu}$ erwarten war, da es sich ausnahmslos um Erze handelt, nämlich um Molybdänglanz, Pyrit, Bleiglanz,

1 Zeitschrift für Radioaktivität und Elektronik, 4, 138 (1907).

2 Schwed. Akad. der Wiss. zu Stockholm, 51, 545 (1894). 
Fahlerz, Antimonglanz, Magneteisen, Zinnerz und Eisenglanz. Es ist nun $\mathrm{zu}$ entscheiden, ob auch bei anderen Krystallen, namentlich bei Oxyden und Salzen, metallische Leitung bei hohen Temperaturen auftritt oder ob wir es hier mit elektrolytischer Leitfähigkeit zu tun haben; diese Frage wird nur experimentell $\mathrm{zu}$ entscheiden sein.

In dieser Hinsicht ist der von Königsberger dargelegte Zusammenhang zwischen Leitfähigkeit und Dissoziationswärme ( $2 q$ in der Formel p. 513) von großem Interesse; allerdings sind diese Wärmen nur für wenige Verbindungen genügend festgestellt und scheint mir die angegebene Grenze zwischen Elektronen- und Ionenleitung mit dem Werte von $2 q=40000$ cal. vielleicht doch noch nicht genügend gestützt.

Bezüglich der Dissoziationswärme ist noch zu bemerken, daß bei Eisenglanz sich verschiedene Werte für dieselbe nach verschiedenen Richtungen ergeben, was für jene Wärmegröße wohl wenig wahrscheinlich ist; daher ist es doch unsicher, ob die berechneten Zahlen ganz richtig sind.

Ferner kann zur Entscheidung der betreffenden Frage das Vorkommen eines Minimalpunktes in der-Temperaturkurve, der bei elektrolytischer Leitung nicht vorkommt, herangezogen werden, wobei allerdings dieser Minimalpunkt bei Temperaturen liegen kann, die praktisch schwer erreichbar sind. Es kann auch dieser Minimalpunkt nicht prägnant genug hervortreten, so daß dieses Merkmal versagen kann.

EinfluB von Beimengungen. Es wurde bereits auf einen solchen hingewiesen (p. 495).

Bei den natürlichen und wohl auch künstlichen Sulfiden sollte aber nicht vergessen werden, daß dieselben wahrscheinlich neben ihren konstitutiven Bestandteilen Metall und Schwefel (oder Antimon, Arsen) auch kleine Mengen von Metall und in einzelnen Fällen auch von Schwefel enthalten können, wodurch ihre Leitfähigkeit stark beeinflußt werden kann; so ist im Schwefelkupfer $\mathrm{Cu}_{2} \mathrm{~S}$ (Kupferglanz) ein Gehalt von metallischem Kupfer wahrscheinlich. ${ }^{1}$ Groß ist der Einfluß bei unreinen Zinnsteinen.

1 Lorenz, 1. c., II, 168. 
Der Einfluß der Beimengungen auf die Leitfähigkeit kann ein erheblicher sein und dabei lassen sich solche Beimengungen nur bei durchsichtigen Krystallen unter dem Mikroskop konstatieren, während sie bei undurchsichtigen metallischen Substanzen unter Umständen gar nicht zu konstatieren sind. Insbesondere ist der Fall denkbar, daß bei Erzen sowohl Schwefel wie auch die Metalle als feste Lösungen vorkommen, wodurch ebenfalls die Leitfähigkeit geändert werden kann.

Königsberger hat darauf aufmerksam gemacht, daß die Beeinflussung der Leitfähigkeit von dem Werte der Dissoziationswärme $q$ (in der Formel p. 513) abhängt; so hat Clay darauf hingewiesen, daß bei Gold, dessen $q$ sehr klein ist, schon einige Tausendstel Prozent größere Änderungen hervorbringen. Bei solchen Substanzen kann sich der Minimalpunkt nicht ausprägen, was ihn mit dem unscharfen Siedepunkt von Stoffen mit sehr kleiner Verdampfungswärme in Zusammenhang bringt, z. B. in der Nähe des kritischen Punktes.

\section{Zusammenhang optischer Eigenschaften mit der elektrischen Leitfähigkeit.}

Nernst ${ }^{1}$ schlos auf Grund der elektromagnetischen Lichttheorie, daß die farblosen und durchsichtigen Oxyde die Elektrizität nicht metallisch leiten, da metallische Leiter die elektromagnetische Energie der Lichtschwingungen in Joule'sche Wärme umsetzen, d. h. das Licht absorbieren. In der Lichtabsorption und Lichtemission liegt also ein Unterscheidungsmerkmal zwischen elektrolytischer und metallischer Leitung.

Dagegen kommt Königsberger ${ }^{2}$ zu entgegengesetzten Resultaten bezüglich jener Oxyde. Er erklärt die bei hohen Temperaturen entstehende plötzliche Weißglut von Oxyden wie Quarz, Zirkonoxyd, Magnesia, Thoroxyd, mit dem Zusammentreffen zweier Kurven, nämlich der Strahlungskurve und der Widerstandskurve, die bei diesen Temperaturen für Quarz sehr steil sein soll.

1 L. c.

2 Physik. Z., VII, 577 (1906). 
Letzteres stimmt aber wohl nicht ganz, denn von $1300^{\circ}$ an ist diese Kurve ziemlich flach. Königsberger meint, daß feste krystallinische Körper in negative Elektronen und positiv geladene Moleküle, Flüssigkeiten in negative und positive Ionen zerfallen; als Beispiele für kontinuierliche Emission und ihre Vergleichung mit der Leitfähigkeit führt er Quarz, Zirkon und Ceroxydul an. Was nun das Parallelgehen der selektiven Absorption und der kontinuierlicheren Lichtemission mit der metallischen Leitfähigkeit anbelangt, so ergab sich diese aus dem Maxwell'schen Gesetz, doch liegen nur wenige Messungen vor und auch die Königsberger'schen Messungen ergeben nicht immer volle Übereinstimmung mit der Maxwell'schen Formel.

Dagegen gibt Königsberger an, daß bei Gemengen von Oxyden mit Salzen, z. B. Kalisilikaten mit überschüssiger Kieselsäure, bei $900^{\circ}$ elektrolytische Leitung bei weitem überwiegt; dies müßte aber dann der Fall sein beim Adular, bei dem er jedoch keine elektrolytische Leitfähigkeit annimmt.

Ich betrachte allerdings solche Körper (z. B. auch Porzellan) nicht als Gemenge von Oxyden, sondern als kieselsaure Salze und bei diesen tritt auch in der Nähe des Schmelzpunktes nachweisbar elektrolytisches Leitvermögen, wie im schmelzflüssigen Zustande auf, es unterscheiden sich $z$. B. die Feldspate nur quantitativ von den von Lorenz untersuchten Salzen, bei denen weit unter dem Schmelzpunkte Polarisation nachweisbar ist.

Die Maxwell'sche Beziehung. Nach Maxwell ist

$$
n^{2} x=\sigma \tau,
$$

wenn $n$ der Brechungsquotient gegen das Vakuum, $x$ der Absorptionsindex, $\sigma$ die absolute Leitfähigkeit des Stoffes, $\tau$ die Dauer der elektromagnetischen Schwingung bedeutet. Doch gilt diese Beziehung nur für lange Wellen, bei Quecksilber hat sie sich für gelbes Licht nicht bestätigt.

J. Königsberger hat die Durchlässigkeit, das Reflexionsvermögen und den Schwächungskoeffizienten bei Antimonglanz, Markasit, Pyrit, Molybdänglanz, Manganit und Fahlerz mit Bezug auf die Maxwell'sche Beziehung zwischen Absorptionsvermögen und elektrischem Leitvermögen bestimmt. Wie aus 
der Aufzählung hervorgeht, sind dies lauter metallische, bei gewöhnlicher Temperatur gut leitende Körper. Er berechnet ${ }^{1}$ aus der soeben angegebenen Formel die Formel für den Schwächungskoeffizienten $a$ der Strahlung

$$
a=\frac{4 \cdot 02 \cdot 10^{5}}{n} \sigma^{\prime}
$$

wobei $\sigma$ die auf $\mathrm{Hg}=1$ bezogene Leitfähigkeit ist. Für Metalle trifft diese Beziehung zu; ob für Oxyde, Sulfide und Sulfosalze, wollte Königsberger durch seine Messungen erproben.

Für gutleitende Metallsulfide und -oxyde ist die Absorption langer Wärmewellen nach Königsberger ${ }^{1}$ nicht viel kleiner, als sie sich nach der Maxwell'schen Beziehung aus der Leitfähigkeit berechnet, während für schlechtleitende Metalloxyde und -sulfide die Absorption größer ausfällt. So nähert sich Molybdänglanz, der ein schlechter Leiter ist, mit der Erwärmung dem Verhalten gutleitender Metallsulfide und Metalle. Die Untersuchungen ergaben, daß nur Bleiglanz und Eisenglanz, die bei gewöhnlicher Temperatur gute Leiter sind, der Maxwellschen Beziehung folgen, die anderen ergaben überaus große Abweichungen.

Bei Antimonglanz $\mathrm{Sb}_{2} \mathrm{~S}_{3}$ verlangt die Maxwell'sche Beziehung einen $10^{7} \mathrm{mal}$ kleineren Schwächungskoeffizienten, bei Markasit ist der Schwächungskoeffizient 120 mal größer, als aus der Leitfähigkeit zu berechnen wäre; bei Pyrit ist die beobachtete Absorption zehnmal kleiner, bei Molybdänglanz fünfmal größer als die Maxwell'sche Beziehung verlangt, bei Manganit ist sie 200 mal größer, bei Fahlerz zehnmal und nur bei einer Substanz, dem Eisenglanz, stimmten Berechnung und Beobachtung vollkommen.

W. W. Coblentz kam zu dem Resultat, daß je kleiner das elektrische Leitvermögen, desto größer die experimentell gefundene Absorption für lange Wellen gegenüber der theoretisch berechneten ist. Bei großem Leitvermögen ist die Absorption kleiner als die aus dem Leitvermögen berechnete.

1 Zentralblatt für Mineralogie, Geologie etc., 1905, p. 460. 
Königsberger hat in seinem erwähnten Aufsatz weitere sehr beachtenswerte Mitteilungen gebracht, z. B. über sehr interessante Beziehungen zwischen Leitfähigkeit und Eigenschwingungen im Ultrarot, dann über den Zusammenhang zwischen dem Wert von $2 q$ (p. 513), beziehungsweise der Affinität des negativen Elektrons zu einem Element und den chemischen Eigenschaften dieses Elementes oder seiner Verbindungen. Alle diese Beziehungen sind allerdings erst noch durch das Experiment zu beweisen.

Ich möchte hier noch auf den Zusammenhang zwischen Phosphoreszenz durch Kathoden-oder Radiumstrahlen und der elektrischen Leitfähigkeit hinweisen; die stark phosphoreszierenden Krystalle: Diamant, Rubin, Saphir, Kalkspat, Kunzit, Quarz, Wollastonit, Steinsalz, Apatit und Flußspat sind lauter Isolatoren, die keine Elektronenleitung zeigen, dagegen sind die nicht phosphoreszierenden: Bleiglanz, Pyrit, Zinnstein, dunkle Zinkblende, Magneteisen und Eisenglanz metallische Leiter.

Allerdings kann die Phosphoreszenz auch sekundär bewirkt sein durch Einschlüsse in Mineralien (vielleicht kommen manchmal solche von radioaktiven Substanzen in Betracht).

Die helle Zinkblende, welche durchsichtig ist, leitet bei gewöhnlicher Temperatur nicht. Demnach sind es also die undurchsichtigen Stoffe, welche bei gewöhnlicher Temperatur leiten, an denen Elektronenleitung sichergestellt ist. Bei Quarz, Saphir, Rutil und durchsichtigen Stoffen, die sich in vielen Eigenschaften den salzartigen Verbindungen nähern, ist Elektronenleitung keineswegs nachgewiesen. Manche Körper mögen eine Mittelstellung einnehmen. Jedenfalls verhalten sich Quarz oder Saphir wie etwa Flußspat und andere durchsichtige Salze, dagegen Zinnstein, Magneteisen und EisenglanZ wie die Sulfide und Metalle. Da a priori keine Entscheidung möglich ist, müssen die Experimentaluntersuchungen entscheiden, namentlich in bezug auf die halbmetallischen Körper.

Königsberger rechnet aus theoretischen Gründen $z u$ den Stoffen mit Elektronenleitung auch Körper, die bei gewöhnlicher Temperatur Isolatoren sind, wie Quarz, Magnesiumoxyd und sogar Silikate wie Adular. Ich glaube, daß aus dem Verhalten dieser Körper bei hoher Temperatur ihre elektrolytische 
Leitfähigkeit hervorgeht, die schon kurz unterhalb des Schmelzpunktes ganz unzweifelhaft auftritt. Königsberger erwähnt auch den Quarz als Oxyd basischen Charakters, was jedoch kaum zutreffen dürfte.

\section{Methode der Untersuchung.}

Man kann bei unseren Leitfähigkeitsversuchen auch gepreßte Pulver anwenden, wie es Streintz ${ }^{1}$ getan hat, oder Schmelzmassen wie Lorenz, ${ }^{2}$ Horton ${ }^{3}$ etc., oder endlich Krystalle. Letztere sind unter allen Umständen vorzuziehen, da sie allein den natürlichen Verhältnissen gleichkommen, ferner nicht wie bei aus Schmelzfluß erstarrten Massen Glasreste darin vorkommen können oder durch verschiedene Korngröße verschiedene Leitfähigkeit erzeugt werden kann, was, wie ich konstatierte, bei Silikaten $z$. B. vorkommt. Beide sind aber den gepreßten Pulvern vorzuziehen, was schon Königsberger hervorgehoben hat.

Die Beschaffung von tadellosen Krystallen ist aber doch mit Schwierigkeiten verknüpft, weil nur solche brauchbar sind, die frei von Einschlüssen sind, die keine Sprünge oder sonstige Inhomogenitäten zeigen; außerdem müssen solche Krystalle auch eine gewisse Größe haben; alle diese Bedingungen sind oft schwer $z u$ erfüllen, so daß aus einer großen Anzahl von Mineralien derartig geeignetes Material überhaupt nicht zu beschaffen ist. Daher ist die Ausdehnung der Untersuchungen beschränkt. Gepreßte Pulver möchte ich wegen der Kohärerwirkung lieber ausschließen, Schmelzen sind zum Teil aus den früher angegebenen Gründen nicht anwendbar, weil bei der Umschmelzung der erstarrte Körper chemisch oder physikalisch verändert wird, so bei Granat, Magneteisen, Topas, Wolframit, Quarz; in diesen Fällen ist die Untersuchung von erstarrten Schmelzen nicht statthaft.

Horton ${ }^{4}$ hat z. B. Quarz untersucht; da er aber umgeschmolzenen Quarz anwandte, so bezieht sich seine Unter-

1 Elektrische Leitfähigkeit gepreßter Pulver, 1904.

2 Elektrolyse geschmolzener Salze, 1. c.

3 L. c.

4 L. c. 
suchung in Wirklichkeit auf Quarzglas, welches eine andere Leitfähigkeit zeigt als krystallisierter Quarz; mikroskopische Untersuchung auf Glasreste ist bei umgeschmolzenen Krystallen notwendig, namentlich wenn es sich um Bestimmung der Polarisation behufs Nachweises elektrolytischer Leitfähigkeit handelt.

Bei der weiteren Frage, ob diinnere Krystallplatten oder dickere Stäbe $z u$ verwenden sind, ist die Auswahl von der Natur des zu untersuchenden Körpers abhängig. Bei guten metallischen Leitern ist letztere Disposition vorzuziehen, bei Isolatoren erstere. Da von mir fast nur Körper untersucht wurden, welche letzterer Klasse angehören, so habe ich Platten von $1 \mathrm{~cm}^{2}$, welche $1 \mathrm{~mm}$ dick waren, untersucht, da sonst bei schiechtleitenden Körpern die Widerstände enorm groß geworden wären; auch bieten nicht alle Krystalle die Möglichkeit der Anfertigung von Stäben. Letztere sind vorzuziehen, wo es sich um große Leitfähigkeit handelt, also bei Körpern, die schon bei nicht sehr hoher Temperatur gut leiten. Wo es sich wie hier jedoch namentlich darum handelt, Polarisation nachzuweisen, darf kein zu großer Widerstand vorhanden sein, da dann der Ladungsstrom zu schwach ist. Man muß also dünne Platten verwenden, wodurch andrerseits die Bestimmung der Widerstände wieder weniger genau wird.

Ich kann, was die Methode der Untersuchung anbelangt, mich auf meine frühere Arbeit über die Leitfähigkeit fester Silikate beziehen, da derselbe Gang bei der Untersuchung eingehalten wurde. Auch habe ich damals die Schwierigkeiten erörtert, welche durch Übergangswiderstände am Kontakt mit den Platinelektroden entstehen, ferner die Fehler, welche durch die längs der Spaltrichtungen eingelagerte dünne Luftschicht entsteht, wodurch die Widerstände vergrößert werden. Die Übergangswiderstände werden aber am besten, wenn auch nicht ganz, vermieden, wenn man die Elektroden an die vergoldete Krystallplatte durch Glimmerplatten anpreßt, welche in einem Kaolintrog stecken (vgl. p. 3 meiner Abhandlung über Leitfähigkeit fester Silikate ${ }^{\mathbf{1}}$; insbesondere wenn man zuerst

1 Sitzungsber. der Wiener Akad., 117, 847 (1908). 
eine Erhitzung bis zirka $1000^{\circ}$ vornimmt, weil dann durch die Ausdehnung des Glimmers die Platinelektroden fest an die Flächen der Krystallplatte angepreßt werden. Die Werte, die man bei einer zweiten Erhitzung erhält, sind dann viel genauer als bei der ersten, sie fallen demgemäß auch kleiner aus. Dies ist aber natürlich nur dann anwendbar, wenn nicht bei höheren Temperaturen Zersetzung eintritt. Wo dies, wie bei Granat, Magnetit der Fall ist, muß man die Werte der ersten Erhitzung verwenden oder darf überhaupt nicht stark erhitzen und dann ist es besser, die Krystallplatte in eine Schraube einzupressen. Ich habe durch die Gefälligkeit der Firma Krupp in Berndorf eine solche Schraube aus Nickel anfertigen lassen können und dieselbe in einigen Fällen verwendet; nur hat jede Schraube den Übelstand, daß die Krystallplatten leichter brechen als bei der Einspannung in den Kaolintrog, bei welcher sich das Anpressen von selbst bei steigender Temperatur vollzieht.

Der Kontakt kann durch Vergolden der Krystallplatte verbessert werden; das Platinieren hatte wegen geringer Haltbarkeit wenig guten Erfolg.

Um Oxydationen des Minerals zu verhindern, kann man den Versuch auch in einer Stickstoffatmosphäre vornehmen.

Selbstverständlich können bei niederen Temperaturen durch Einschlüsse von Flüssigkeiten Fehler eintreten, wie in manchen wieder im entgegengesetzten Sinne durch Einschlüsse von Krystallen, wodurch die metallische Leitfähigkeit vergrößert wird; bei Sulfiden und Sulfosalzen dürfte dies vielleicht mitunter Fehler bewirken:

Da bei meinen Versuchen die Leitfähigkeit bei höherer Temperatur beginnt, so kann sie nicht wie bei manchen natürlichen Sulfiden ${ }^{1}$ von okkludierten Lösungen herrühren. Die unipolare Leitung der Sulfide kommt dadurch zustande, daß die wässerigen Lösungen, welche als Einschlüsse in den Sulfidmineralien vorhanden sind, elektrolytisch leiten und sich Sauerstoff in der Nähe der Kathode entwickelt, der das Sulfid zu Sulfat oxydiert. Infolgedessen sinkt bei längerem Stromdurchgang die Leitfähigkeit und die Leitung kann ganz aufhören.

1 O. Weigel, N. Jahrb. für Min., Beil,, 21, 325 (1905). 
Genauigkeit der Messung. Fehlerquellen. Was nun die Genauigkeit der Messungen anbelangt, so ist diese nur bei höherer Temperatur eine zufriedenstellende; denn bei niederen Temperaturen ist der Kontakt sehr schwer herstellbar, ob man nun eine Presse nimmt oder ob man, wie ich es meistens tue, durch Glimmerplatten Platinelektroden anprebt. Dies ist jedoch nur in den wenigsten Fällen störend, da wir es ja meistens mit Körpern zu tun haben, die erst bei hohen Temperaturen Leitfähigkeit zeigen. Da aber auch bei höheren Temperaturen der Temperaturkoeffizient ein sehr großer ist, so werden leicht zwei Messungsreihen nicht ganz übereinstimmende Resultate geben; sehr große Unterschiede würden auf Übergangswiderstände schließen lassen.

Sehr wichtig ist die genaue Bestimmung der Temperatur, da ein Unterschied von $10^{\circ}$ schon einen Unterschied in dem Widerstand verursacht. Die Messung wird mit dem Platin-PlatinRhodiumelement und einem Galvanometer von Siemens \& Halske durchgeführt; oft wurden die Messungen auf zwei Galvanometern abwechselnd verglichen. Das Thermoelement ruht in nächster Nähe der Krystallplatte auf dem Kaolintrog; auf möglichst langsames Anheizen wurde stets gesehen.

Bei den Widerstandsbestimmungen muß die Temperatur konstant erhalten werden, was bei meiner Disposition, bei welcher die Temperatur durch drei verschiedene Widerstände reguliert wurde, auch leicht für über eine halbe Stunde lang gelingt.

Widerstandsbestimmungen bei langsam aufsteigender Temperatur sind solchen bei absteigender vorzuziehen, da die Regulierung besser gelingt; will man bei absteigender Temperatur Messungen ausführen, so soll sehr langsam abgekühlt werden.

Die Unterschiede, welche man oft bei derselben Krystallplatte bei zwei Versuchsreihen erhält, rühren davon her, daß das Gleichgewicht sich schon bei etwas verschiedener Erhitzung schneller oder langsamer einstellt und daher der gemessene Widerstand wegen der verschiedenen Temperatur der Platte ungleich ist; außerdem ist aber mitunter, wie erwähnt, bei niederen Temperaturen mangelhafter Kontakt daran schuld. 
Messung der Polarisation. Das wichtigste Kriterium für die Frage, ob Ionen- oder Elektronenleitung vorliegt, ist die Messung der Polarisation.

Der Vorgang bei der Messung des Polarisationsstroms ist folgender: Es wird durch die Mineralplatte im allgemeinen 5 Minuten lang ein Ladestrom geschickt, dann dieser Stromkreis geöffnet und die Zelle durch ein im Nebenschluß geschaltetes Edelmann'sches Drehspulenspiegelgalvanometer entladen. Im Hauptschluß entspricht einem Ausschlag von $1 \mathrm{~mm}$ ein Strom von $2 \cdot 1 \times 10^{-6}$ Milliampere; da der innere Widerstand des Galvanometers $507 \Omega$ beträgt, entsprechen, wenn der Widerstand der Abzweigung $0 \cdot 1,0.5$ oder $1.5 \Omega$ groß gewählt wird, einem Ausschlag von $1 \mathrm{~mm}$ beziehungsweise 0.01065 , $0 \cdot 00213$ oder 0.00071 Milliampere.

Als Stromquelle für den Ladestrom wurde im allgemeinen eine Akkumulatorenbatterie, in vereinzelten Fällen der Straßenstrom (220 Volt) benützt.

Bei dem großen Widerstand der Zelle gingen immer nur einige Milliampere durch, welcher Strom an einem Amperemeter von Siemens \& Halske abgelesen wurde, an dem einem Teilstrich von ungefähr $1 \mathrm{~mm}$ ein Milliampere entspricht.

Bei den Polarisationsversuchen wird der Entladungsstrom zusammengesetzt sein aus dem Polarisationsstrom und einem Thermostrom, außerdem kann durch Peltiereffekt ein Thermostrom entstehen. Der Polarisationsstrom ergibt sich aus der Differenz des ursprünglichen Ausschlages und des nach 5 bis 10 Minuten noch verbleibenden. Dort, wo ein sofortiges Zurückgehen des Zeigers erfolgte, bei der Entladung z. B. bei Wolframit, könnte vielleicht ein sehr großer Reststrom vorliegen.

Den ganzen Ausschlag am Spiegelgalvanometer, der oft recht bedeutend ist und allmählich abfälit, dem Peltiereffekt zuzuschreiben, ist wohl nicht angängig. Vielleicht ist letzterer meistens ein geringfügiger, mit Ausnahme von metallisch leitenden Körpern wie Magneteisen, Wolframit, die ein abnormes Verhalten zeigen, wie wir sehen werden. Wichtig ist auch die etwaige physikalische Veränderung der Krystallplatten sowie der Elektroden nach den Polarisationsversuchen. 
Es ist aber immerhin noch fraglich, ob das Fehlen von Polarisation ein unbedingter Beweis gegen die elektrolytische Leitfähigkeit ist; nach $\mathrm{Haßlinger} \mathrm{kann} \mathrm{auch} \mathrm{bei} \mathrm{Gegenwart}$ solcher Polarisation fehlen, er meint, daß bei hohen Temperaturen auch Silbersulfid elektrolytisch leite. $\mathrm{Ob}$ die Hypothese von Haßlinger, wonach auch Metalle Ionen haben, die aber im Gegensatze zu den Ionen der Elektrolyte sich nur durch ihre Ladung unterscheiden, richtig ist, wage ich nicht zu entscheiden. Die Ausführungen Haßlinger's sind sehr bestechend, aber doch stark hypothetisch.

Störungen durch Reststrom. Die Ansicht, daß bei manchen Körpern keine elektrolytische Leitung trotz verhältnismäßig geringerer Widerstände vorliege, findet ihre Stütze hauptsächlich in dem im festen Zustande verhältnismäßig geringer, als zu erwarten war, befundenen Polarisationsstrom. Es ist daher auch von Königsberger die Vermutung ausgesprochen worden, daß der ganze Polarisationsausschlag einem Peltiereffekt zuzuschreiben sei.

Es ist aber möglich, daß bei diesen Körpern der Reststrom ungewöhnlich groß ist, indem z. B. das abgeschiedene Metall sich sofort wieder oxydiert. Nernst hat schon darauf aufmerksam gemacht, daß bei hohen Temperaturen der Reststrom sehr groß sein wird; es dürfte dies bei unseren hohen Temperaturen auch der Fall sein, obgleich sich vorläufig in den einzelnen Fällen nicht immer übersehen läßt, wie dieser Reststrom zustande kommt, ob durch Auflösen z. B. von Sauerstoff in der Schmelze, durch Lösung von Metalloiden in dieser oder von Metallen; auch Löslichkeit von Gasen in den Elektroden ist möglich; Bildung höher oder auch niedriger oxydierter Verbindungen ist nicht ganz ausgeschlossen. Es können mitunter bei festen Körpern in der Nähe des Schmelzpunktes Verhältnisse wie bei Schmelzen eintreten. ${ }^{2}$

$\perp$ Zeitschrift für Elektrochemie, 6, 41 (1899); vgl. auch Bose, Ann. der Physik, 9, 164 (1902).

2 Siehe darüber: R. Lorenz, Elektrolyse geschmolzener Salze, III, 4, Uber Depolarisation, p. 45 bis 57. 


\section{Graphische Darstellung der Versuchsresultate.}

Wie gewöhnlich wurde das Resultat derart dargestellt, daß auf der Abszissenachse die Temperaturen von $50 \mathrm{zu} 50^{\circ}$, auf der Ordinatenachse die Widerstände in Ohm, beziehungsweise in $1000 \mathrm{Ohm}$ aufgetragen wurden. In einigen Fällen wurde die früher ${ }^{1}$ bereits verwendete Darstellung, wonach auf der Abszissenachse $\frac{1}{T}$, auf der Ordinatenachse $\log W$ aufgetragen wird, benützt.

Es resultiert diese Darstellung aus der van't Hoff'schen Gleichung

$$
\frac{d \ln x}{d T}=-\frac{q}{R T^{2}} .
$$

E. Rasch und F. W. Hinrichsen ${ }^{2}$ leiten daraus $a b$

$$
\frac{d x}{x}=\frac{\nu^{\prime} \cdot d T}{T^{2}}
$$

$x$ ist die Leitfähigkeit, $v^{\prime}$ eine Wärmegröße. Das Integral der letzten Gleichung kann auf die Form gebracht werden

$$
\log W=\frac{\nu^{\prime}}{T}+C
$$

wobei $W=\frac{1}{x}$ der spezifische Widerstand, $C=\log W \infty$ ist.

Die Formel ist namentlich für die Fälle sehr anwendbar, wo man flüssigen und festen Zustand eines Stoffes in bezug auf die Leitfähigkeit vergleichen will, da man dann zwei getrennte Kurvenstücke erhält und daraus z. B. bei Albit, Labradorit, Diopsid ersieht, ${ }^{3}$ daß der Temperaturkoeffizient im festen Zustand sehr groß, im flüssigen dagegen sehr gering ist.

Bei vielen Körpern ist die nach jener Formel aufgetragene Temperaturkurve eine gerade Linie, beim Übergange vom

1 C. D o elter, Dissoziation der Silikatschmelzen, II. Sitzungsber. derWiener Akad., 117, 300 (1908).

2 Nach Königsberger ist die Priorität nicht den genannten Autoren zuzusprechen, er nentit die Formel die Arrhenius-Kohlrausch-Heydweiller'sche. Zeitschrift für Elektrochemie, 14, 41 (1908) und 15, 100 (1909).

3 C. Doeltex, Dissoziation der Silikatschmelzen, II, p. 25. 
flüssigen zum festen Zustande tritt ein Sprung ein; indessen tritt bei Silikaten doch ein allmähliches Umbiegen der Kurve vor dem Schmelzpunkte ein. ${ }^{1}$

Königsberger ${ }^{2}$ hat für Körper mit Elektronenleitung eine andere Formel aufgestellt, da nach ihm jene Formel, die eine Abnahme des Widerstandes mit der Temperatur ergibt, nur in erster Annäherung gilt; er schlägt die Formel vor:

$$
W=w_{0}\left(1+\alpha t \pm \beta t^{2}\right) e^{-q \frac{t}{[t+273] 273}},
$$

worin $W$ der Widerstand bei $t, w_{0}$ der Widerstand bei $0^{\circ} \mathrm{C}$, $\alpha, \beta$ die Temperaturkoeffizienten bei vollständiger Dissoziation, also die der Metalle, bedeuten; $2 q$ ist das $q^{\prime}$ in der früheren Formel der van't Hoff'schen Gleichung

$$
\frac{d x}{d T}=\frac{q^{\prime}}{2 T^{2}}
$$

Es ist $2 q$ die Ionenenergie oder Vereinigungswärme ElektronMetallion von 1 Grammolekül oder die Dissoziationswärme pro Grammolekül des negativen Elektrons.

Aus der Formel berechnet Königsberger auch den Minimalpunkt der Leitfähigkeit-Temperaturkurve, der bei metallischer Leitfähigkeit hervortritt. Bei Pyrit, Magnetkies liegt das Minimum zwischen 0 und $300^{\circ}$.

Königsberger benützt ferner diese Formel, um daraus die Größe von $q$, also die Dissoziationswärme des negativen Elektrons eines Atoms zu berechnen, dann berechnet er auch die Dissoziationswärmen von Verbindungen und glaubt, daß die Grenze zwischen Ionenleitung und Elektronenleitung bei $q=20.000$ cal. liege.

\section{Die Versuchsergebnisse.}

In den Kreis der Messungen wurden neben Salzen auch Oxyde und solche Körper einbezogen, welche sowohl als

1 C. Doelter, Dissoziation der Silikatschmelzen, II, p. 25.

2 Zeitschrift für Elektrochemie, 15, 100 (1909). 
Gemenge von Oxyden oder besser als Salze betrachtet werden können, wie Chrysoberyll $\mathrm{Be}_{2} \mathrm{O}_{4}$ oder $\mathrm{BeO}, \mathrm{Al}_{2} \mathrm{O}_{3}$, MagnetII III

eisen $\mathrm{FeO}, \mathrm{Fe}_{2} \mathrm{O}_{3}$ oder $\mathrm{FeFe}_{2} \mathrm{O}_{4}$. Von Silikaten waren von mir bereits Diopsid und Adular untersucht worden, jetzt kamen dazu noch Granat und Topas.

Es wäre ja wünschenswert gewesen, auch weitere Krystalle zu erproben; dies scheiterte jedoch an dem Umstande, daß viele Krystalle verunreinigt oder in guten Platten überhaupt nicht zu haben sind.

\section{Zinnstein $\left(\mathrm{Sn}_{2}\right)$.}

Der Zinnstein ist besonders interessant, weil er zwischen metallischen Körpern und nichtmetallischen eine Art Zwischenstellung einnimmt. Er zeigt verschiedene Grade der Durchsichtigkeit und verschieden intensive Farben; es kommen farblose bis schwarze Zinnsteine vor. Dann zeigen größere Schnitte auch verschiedenfarbige Zonen. Diese Zonen scheinen nun bezüglich des elektrischen Leitvermögens sich sehr verschieden $\mathrm{zu}$ verhalten. Den dunklen Teil eines $Z_{\text {innsteins }}{ }^{1}$ haben J. Königsberger und $\mathrm{O}$. Reichenhein schon früher untersucht; sie fanden keinen Unterschied bei der Messung mit Gleichstrom und Wechselstrom, konnten jedoch die Temperaturkurve nur $z$ wischen -74 und $133^{\circ}$ verfolgen; sie erhielten stets sehr geringe Widerstände unter $1 \mathrm{Ohm}$. Reines durchsichtiges Zinndioxyd ist jedoch nach diesen Autoren als Nichtleiter zu betrachten, während sich die obigen Daten auf einen aus einem Krystall herausgeschnittenen undurchsichtigen, dunklen Stab beziehen. ${ }^{2}$

Was dieser in vielen Zinnsteinen beobachtete schwarze Teil ist, bleibt vorläufig noch unklar; wahrscheinlich liegt ein diluter metallischer Farbstoff vor. Becke ${ }^{3}$ wies nach, daß gerade dunkle Zinnsteine nur $0.13 \mathrm{Fe}_{2} \mathrm{O}_{3}$ enthielten, also ist

1 Beyeringk ätzte einen nichtleitenden Zinnstein mit Flußsäure, welcher dadurch leitend wurde.

2 N. J. f. Mineral. (1906), II, 31.

3 Ts chermak's Min. Mitt. (1877), 243. 
nicht Eisen der färbende Bestandteil. Auch Wolfram wurde von Kohlmann ${ }^{1}$ vermutet; angesichts der großen Leitfähigkeit des Wolframits (p. 543) wäre eine Beimengung von Wolframit nicht unmöglich. Ts chermak ${ }^{2}$ erwähnt Tantal als Beimengung, möglicherweise handelt es sich um eine Tantalverbindung.

Königsberger ließ eine dunkelgefärbte Partie untersuchen und fand darin Titanoxyd und Eisenoxyd.

Eswäre daher auch die Möglichkeit einer Beimengung von Rutil oder eher von Titaneisen gegeben; man kann sich überzeugen, daß die dunklen Teile parallel mit dem normalen durchsichtigen Zinnstein verwachsen sind, und zwar wahrscheinlich parallel einer Deuteropyramide des Zinnsteins. Da Eisenoxyd und Rutil bekanntlich miteinander parallele Verwachsungen bilden, wäre es möglich, daß auch Titaneisen und Eisenglanz mit dem Zinnstein, der ja isomorph mit Rutil ist, verwachsen wären; aber es

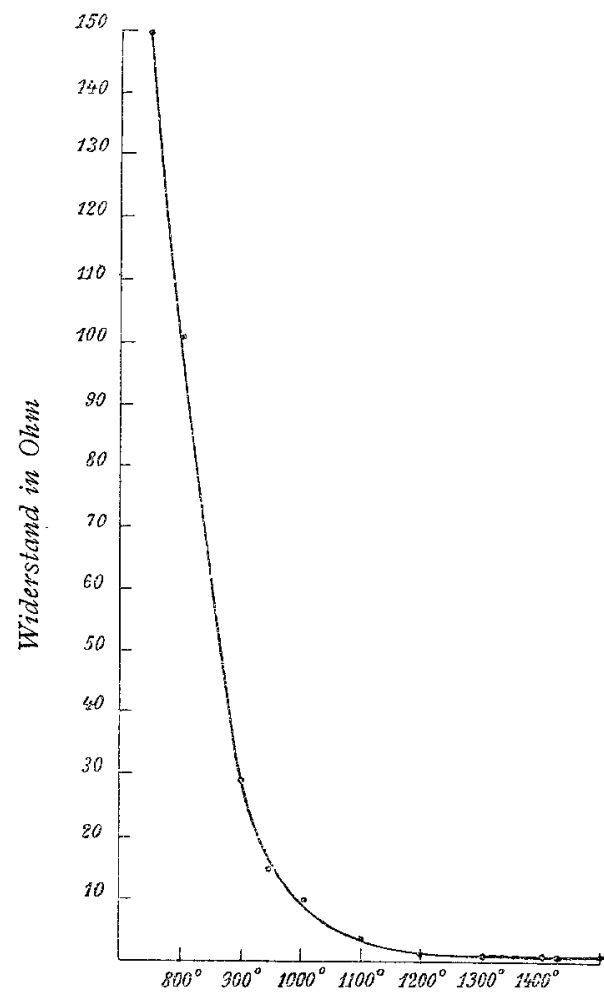

Fig. 1. Zinnstein. handelt sich dabei mehr um ein Pigment im hellen Zinnstein, das jedoch eine krystallographische Orientierung besitzt wie parallele Verwachsungen.

1 Kohlmann, Z. f. Kryst., 24, 350 .

2 Mineralogie, p. 455. 
Beyeringk ${ }^{1}$ hat elektrolytische Wirkung bei Zinnstein dadurch erhalten, daß er ein Stück Zinnstein auf Zinkblech in Salzsäure legte; das Mineral beschlägt sich mit Zinn.

Derselbe Autor hat Zinnstein von Altenberg senkrecht und parallel zur Hauptachse auf Leitfähigkeit untersucht und fand Abnahme des Widerstandes bei Temperaturerhöhung bis $225^{\circ}$.

Königsberger und Reichenhein sind der Ansicht, daß der Zinnstein nicht elektrolytisch leite.

Der von mir untersuchte Zinnstein zeigte an einer Ecke einen undurchsichtigen Fleck; daß dieser kleine dunkle Teil die Leitfähigkeit vergrößert, ist nicht unwahrscheinlich und wäre ohne diesen Teil möglicherweise die Leitfähigkeit eine geringere. Die Krystallplatte zeigte hellgelbe bis rötliche Farbe und die Verteilung der Fig. 2. Farben zeigt Fig. 2. Durch Glühen wurde sie nur Zinnstein. wenig heller; der schwarze Teil erleidet durch Erhitzen auf über $1300^{\circ}$ keine Veränderung. Die auf Leitfähigkeit untersuchte Platte war parallel zur Achse geschnitten.

Zinnstein.

\begin{tabular}{|c|c||c|c||c|c|}
\hline Temperatur & Widerstand & Temperatur & Widerstand & Temperatur & Widerstand \\
\hline \hline $360^{\circ} \mathrm{C}$ & 3550 & $700^{\circ}$ & 1050 & $1150^{\circ}$ & $1 \cdot 7$ \\
400 & 3000 & 750 & 150 & 1200 & $1 \cdot 20$ \\
450 & 1080 & 800 & 102 & 1250 & $1 \cdot 06$ \\
500 & 1060 & 900 & 29 & 1300 & $0 \cdot 96$ \\
550 & 3270 & 950 & 14 & 1360 & $0 \cdot 88$ \\
600 & 2510 & 1000 & $9 \cdot 8$ & 1410 & $0 \cdot 85$ \\
650 & 1890 & 1060 & $5 \cdot 0$ & 1430 & $0 \cdot 85$ \\
& & & & &
\end{tabular}

Zinnstein (Abkühlung).

\begin{tabular}{|c|r||r|r|}
\hline Temperatur & Widerstand & Temperatur & Widerstand \\
\hline \hline 1270 & 0.980 & 1010 & $1 \cdot 688$ \\
1200 & 1.105 & 930 & $\begin{array}{r}2 \cdot 677 \\
1080\end{array}$ \\
& 1.488 & 780 & 55.8 \\
\hline
\end{tabular}

I N. J. f. Mineral., Beilageband XII, 403 (1896). 
Bei Zinnstein ist der Verlauf der Kurve von $550^{\circ}$, von welchem Punkte keine Übergangswiderstände mehr auftreten, ein regelmäßiger. Der Widerstand ist schon bei $360^{\circ}$ nicht hoch und sinkt bei $850^{\circ}$ zum Betrage von wenigen Ohm. Bei hohen Temperaturen ist die Leitfähigkeit eine sehr bedeutende, ein Knickpunkt in der Kurve fehlt.

Polarisation kann hier nicht beobachtet werden; es ergab sich auch bei $1200^{\circ}$ kein meßbarer Polarisationsausschlag.

Daher ist die Wahrscheinlichkeit, daß im Zinnstein Elektronenleitung und nicht Ionenleitung vorhanden ist, ziemlich groß; indessen wäre es möglich, daß bei hohen Temperaturen auch letztere auftritt, und ließe sich die Depolarisation durch Reststrom erklären.

\section{Rutil $\left(\mathrm{TiO}_{2}\right)$.}

Eine wenig durchsichtige Rutilplatte wurde erhitzt und es ergab sich das Resultat, daß bis $950^{\circ}$ keine meßbare Leitfähigkeit eintritt; der Körper hat daher nicht wie der verwandte isomorphe Zinnstein schon bei verhältnismäßig niederen Temperaturen Leitfähigkeit.

Eine Versuchsreihe konnte infolge eines Unfalles, bei welchem die Platte zersprang, nicht ausgeführt werden. Bei $1150^{\circ}$ war der Widerstand $950 \Omega$, also ganz bedeutend höher als bei Zinnstein.

\section{Quarz $\left(\mathrm{SiO}_{2}\right)$.}

Es wurden sowohl Bergkrystalle als auch Rauchquarze untersucht, und zwar stammen erstere von der Schweiz, die letzteren aus Brasilien. Es wurden fast durchwegs Krystallplatten verwendet, die senkrecht zur Achse geschnitten waren; über Platten parallel der Achse sieh meine frühere Arbeit. ${ }^{1}$ Von Quarz wurden zwei Platten, von Rauchquarz zwei untersucht, dann noch eine Quarzplatte parallel zur Achse.

1 Die Leitfähigkeit fester Silikate, l. c. 


\section{Quarz I.}

\begin{tabular}{|c|c|c|c|c|c|}
\hline Zeit & $\begin{array}{c}\text { Tempe- } \\
\text { ratur } \\
\text { vom } \\
\text { Eispunkt } \\
\text { gemessen }\end{array}$ & $\begin{array}{l}\text { Wider- } \\
\text { stand } \\
\text { in Ohm }\end{array}$ & 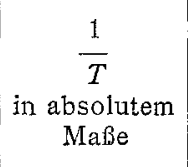 & $\log W$ & \\
\hline \multicolumn{6}{|c|}{ Erste Erhitzung } \\
\hline \multirow[t]{7}{*}{$4^{\mathrm{h}} 35^{\mathrm{m}}$} & $600^{\circ}$ & 8.500 & $1 \cdot 149 \times 10^{-3}$ & $3 \cdot 9294$ & \\
\hline & 680 & 2.300 & $1 \cdot 052$ & $3 \cdot 3617$ & \\
\hline & 6851 & 1.940 & $1 \cdot 047$ & $3 \cdot 2878$ & \\
\hline & $685^{2}$ & 2.920 & $1 \cdot 047$ & $3 \cdot 4653$ & \\
\hline & 710 & 3.980 & $1 \cdot 020$ & $3 \cdot 5999$ & \\
\hline & 730 & 3.700 & $1 \cdot 000$ & $3 \cdot 5682$ & \\
\hline & 750 & 4.280 & $0 \cdot 980$ & $3 \cdot 6314$ & \\
\hline \multirow[t]{5}{*}{455} & 780 & 5.050 & 0.952 & $3 \cdot 7033$ & $\begin{array}{l}\text { Vor der Ladung mit } \\
\text { Akkumulator. }\end{array}$ \\
\hline & 780 & 15.970 & 0.952 & $4 \cdot 2033$ & Nach der Entladung. \\
\hline & 750 & 15.640 & $0 \cdot 980$ & $4 \cdot 1942$ & \\
\hline & 700 & 25.700 & $1 \cdot 031$ & $4 \cdot 4099$ & \\
\hline & 620 & 45.500 & $1 \cdot 124$ & $4 \cdot 6580$ & \\
\hline \multicolumn{6}{|c|}{ Zweite Erhitzung (Fig. 3) } \\
\hline $2^{\mathrm{h}} 15^{\mathrm{m}}$ & $430^{\circ}$ & 61.400 & $1.428 \times 10^{-3}$ & $4 \cdot 788$ & \multirow{15}{*}{$\begin{array}{l}\text { Vor der Ladung. } \\
\text { Nach der Entladung. }\end{array}$} \\
\hline 235 & 480 & 13.800 & $1 \cdot 333$ & $4 \cdot 139$ & \\
\hline 245 & 505 & 10.200 & $1 \cdot 290$ & $4 \cdot 009$ & \\
\hline 305 & 605 & 4.080 & $1 \cdot 143$ & $3 \cdot 611$ & \\
\hline 353 & 6801 & 2.700 & $1 \cdot 053$ & $3 \cdot 431$ & \\
\hline 403 & 6902 & 3.356 & $1 \cdot 042$ & $3 \cdot 525$ & \\
\hline & 730 & 2.800 & $1 \cdot 000$ & $3 \cdot 447$ & \\
\hline 420 & 780 & 6.690 & 0.952 & $3 \cdot 825$ & \\
\hline 435 & 830 & 12.300 & 0.909 & 4.090 & \\
\hline 445 & 880 & 20.300 & 0.869 & $4 \cdot 307$ & \\
\hline 450 & 930 & 24.480 & 0.833 & $4 \cdot 389$ & \\
\hline 500 & 980 & 52.500 & 0.800 & $4 \cdot 720$ & \\
\hline \multirow[t]{2}{*}{515} & 1080 & 20.300 & $0 \cdot 741$ & $4 \cdot 307$ & \\
\hline & 1130 & 10.800 & 0.714 & $4 \cdot 033$ & \\
\hline 520 & 1180 & 7.540 & 0.689 & $3 \cdot 877$ & \\
\hline
\end{tabular}




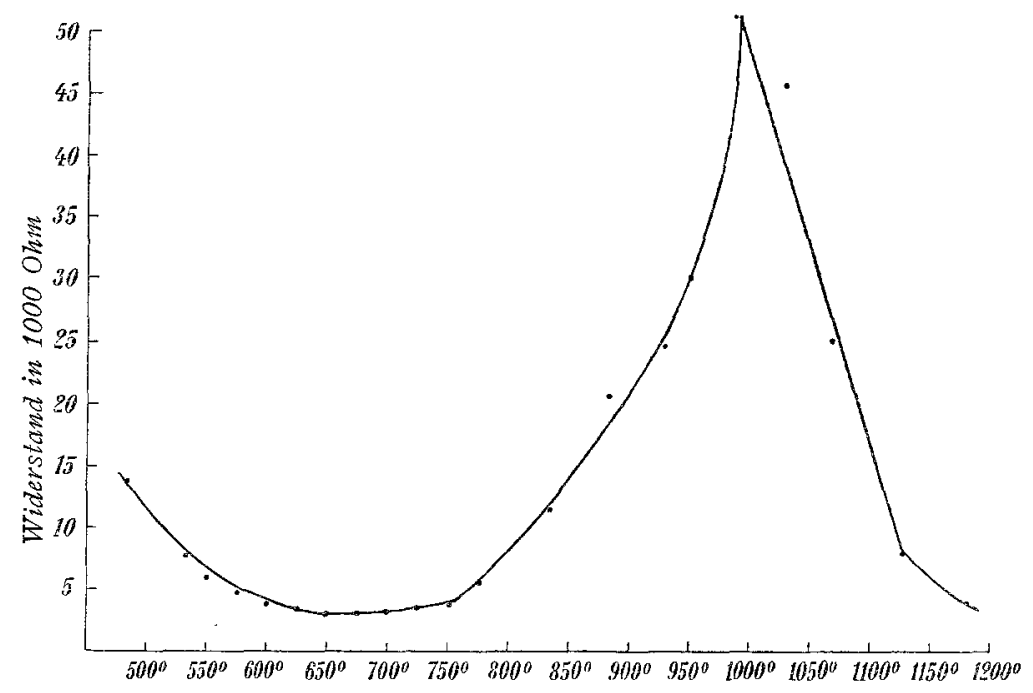

Fig. 3. Quarz I, zweite Erhitzung.

\begin{tabular}{|c|c|c|c|c|c|}
\hline Zeit & $\begin{array}{l}\text { Tempe- } \\
\text { ratur }\end{array}$ & $\begin{array}{c}\text { Wider- } \\
\text { stand } \\
\text { in Ohm }\end{array}$ & 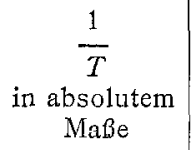 & $\log W$ & \\
\hline \multicolumn{6}{|c|}{ Dritte Erhitzung (Fig. 4 und Fig. 5) } \\
\hline $3^{\mathrm{h}} 00^{\mathrm{m}}$ & 730 & 490.000 & $1 \cdot 000 \times 10^{-3}$ & $5 \cdot 6902$ & \\
\hline 330 & 830 & 323.000 & 0.909 & $5 \cdot 5092$ & \\
\hline 400 & 930 & 107.600 & 0.833 & $5 \cdot 0318$ & \\
\hline 425 & 1030 . & 23.300 & 0.769 & $4 \cdot 3674$ & \\
\hline 438 & 1130 & 13.500 & $0 \cdot 714$ & $4 \cdot 1303$ & \\
\hline 448 & 1180 & 7.540 & 0.689 & $3 \cdot 8774$ & \\
\hline 458 & $1230^{1}$ & 4.180 & $0 \cdot 667$ & $3 \cdot 6212$ & $\begin{array}{l}\text { Ladung mit Akkumu- } \\
\text { lator. }\end{array}$ \\
\hline 510 & $1240^{2}$ & 4.180 & 0.667 & $3 \cdot 6212$ & \\
\hline 525 & 12801 & 2.580 & 0.645 & $3 \cdot 4116$ & $\begin{array}{l}\text { Ladung mit Akkumu- } \\
\text { lator. }\end{array}$ \\
\hline 535 & $1280^{2}$ & 2.580 & 0.645 & $3 \cdot 4116$ & \\
\hline 545 & 1305 & 1.860 & 0.635 & $3 \cdot 2695$ & \\
\hline
\end{tabular}

Bei der ersten Erhitzung sind die Widerstände auffallend gering, da wir bereits bei $685^{\circ}$ unter $2000 \Omega$ angelangt sind. 
Bei der Ladung der Zelle erfolgt nun eine Erhöhung des Widerstandes wohl infolge von Vorgängen, die mit der Elektrolyse zusammenhängen, dann steigt die Leitfähigkeitskurve wieder langsam an, doch wurde hier über $780^{\circ}$ nicht hinausgegangen. Eine optische Untersuchung zeigte keine Veränderung des Interferenzbildes der Platte.

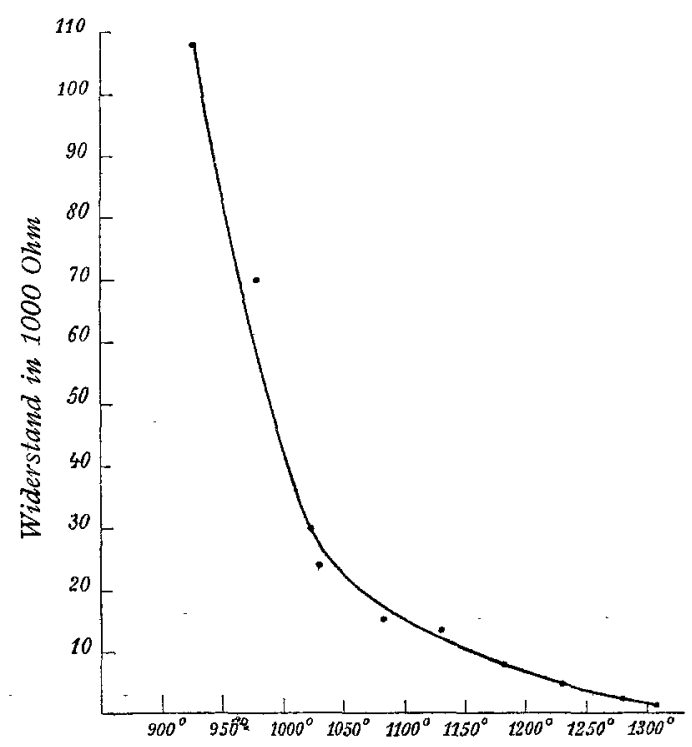

Fig. 4. Quarz I, dritte Erhitzung.

Bei der ersten Erhitzung wurde durch die Ladung bei $685^{\circ}$ eine Veränderung des Widerstandes bewirkt; die Polarisation ist immerhin merklich, wenn auch nicht groß.

Die Widerstände sind sehr gering und deuten auf Gehalt an elektrolytisch leitender Beimengung.

Unter $780^{\circ}$ scheint eine Veränderung stattgefunden $\mathrm{zu}$ haben, da plötzlich nach der Ladung mit dem Akkumulator eine starke Erhöhung des Widerstandes von $5050 \Omega$ auf $15.790 \Omega$ stattfand.

Es hängt diese Veränderung mit der Ladung und der dadurch bewirkten Elektrolyse des Natriumsilikates zusammen, durch welche sich Natrium an der Kathode ausscheidet. Nun ist aber die Temperatur von $780^{\circ}$ der Siedepunkt 
des Natriums und es fing jetzt das Natrium an, sich zu verflüchtigen, daher die Leitfähigkeit abnehmen muß; es nähert sich der Quarz immer mehr dem Zustand, welchen ein reiner Quarz zeigt, und erst bei noch weiterer Temperaturerhöhung haben wir keinen Einfluß der Beimengung mehr; die Kurve fällt dann wieder von $930^{\circ}$ an.

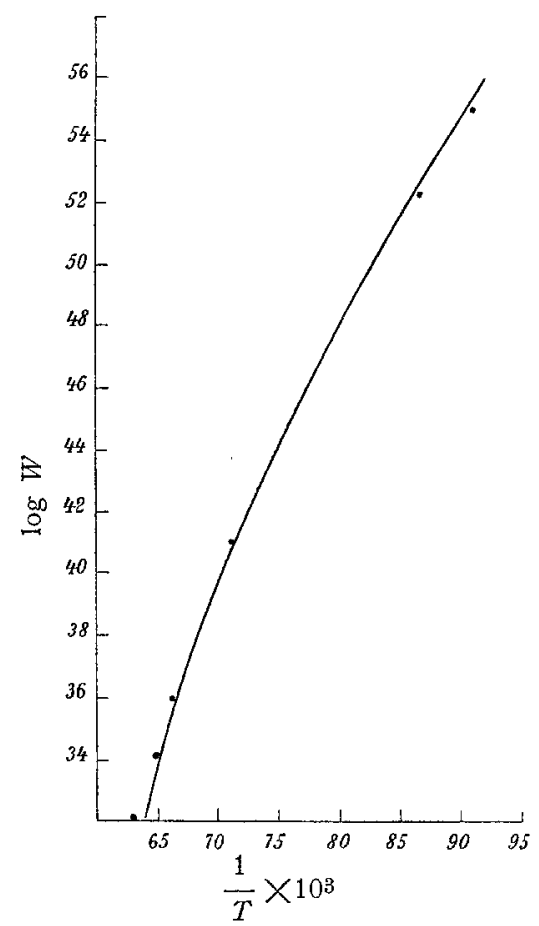

Fig. 5. Quarz I, dritte Erhitzung.

Mit der von Le Chate li er beobachteten Volumsvermehrung des Quarzes und der von Mügge beobachteten optischen Veränderung bei zirka $575^{\circ}$ hat jene Änderung wohl keinen Zusammenhang.

Bei der $z$ weiten Erhitzung sind die Widerstände wieder sehr geringe, die Kurve ist nun eine regelmäßige wieder bis zum Polarisationsversuch bei $680^{\circ}$, worauf wieder nach der Entladung ein Ansteigen des Widerstandes sich bemerkbar macht. Von $730^{\circ}$ an steigt der Widerstand sehr stark und regelmäßig bis $980^{\circ}$, worauf wieder ein langsames Fallen des 
Widerstandes eintritt. Der Punkt von $750^{\circ}$ wäre aber hier nicht als ein Umkehrpunkt zu betrachten, sondern als der Punkt, von welchem an die die elektrolytische Leitung verursachende Beimengung wirkungslos wird; von da an tritt dann die wirkliche Leitfähigkeit allmählich ein und bei $980^{\circ}$ wäre die reine Quarzsubstanz erreicht, daher muß dann der Widerstand wieder fallen.

Bei der dritten Erhitzung zeigen sich dann die hohen wahren Widerstände, die aber immer noch größer sind als die des Quarzes parallel zur Achse, die ich seinerzeit gemessen hatte.

Polarisation. Bei der ersten Erhitzung war der Versuch, welcher bei $685^{\circ}$ unternommen wurde, mit einem Akkumulator ausgeführt worden. Die Ladezeit betrug nur 2 Minuten, der Ladestrom war anfangs $0.5 \mathrm{~m} \mathrm{~A}$, fiel schließlich auf Null. Der Ausschlag bei der Entladung ist $20 \mathrm{~mm}$, was $0.0038 \mathrm{~m} \mathrm{~A}$ und $0 \cdot 11$ Volt entspricht. Als Thermostrom ist nur ein Anteil von $2 \mathrm{~mm}$ zu betrachten, der nach 7 Minuten noch nicht verschwand.

Bei der zweiten Erhitzung war bei dem bei $680^{\circ}$ unter denselben Bedingungen ausgeführten Polarisationsversuch ein Ladungsstrom von $2 m A$, welcher bald abfiel. Der Ausschlag war wie früher $20 \mathrm{~mm}$, d. i. $0.041 \mathrm{~m} \mathrm{~A}$.

Der zweite Versuch bei $1180^{\circ}$ zeigte wieder mit einem Akkumulator einen Ladungsstrom von $1 m$ A. Der Ausschlag ist stark, $55 \mathrm{~mm}$ des Polarisationsstromes entsprechen $0.089 \mathrm{~m} \mathrm{~A}$ beziehungsweise 0.67 Volt, ist also kein geringfügiger.

Bei der dritten Erhitzung dieses Quarzes ergab ein bei $1230^{\circ}$ ausgeführter Versuch einen Ladungsstrom von $1.2 \mathrm{~m} \mathrm{~A}$, die Ladungszeit betrug auch hier 5 Minuten; der Entladungsstrom gibt einen Ausschlag von $45 \mathrm{~mm}$, was nach Abzug des Thermostromausschlages, der nicht mehr abfällt, einer elektromotorischen Kraft des Polarisationsstromes von 0.31 Volt und $0.071 \mathrm{~m} \mathrm{~A}$ entspricht.

Bei der dritten Erhitzung sind die Verhältnisse wieder andere, zuerst bis $750^{\circ}$ ein enormer Widerstand, der nun regelmäßig abfällt, aber gegen früher höhere Werte gibt; erst bei $1300^{\circ}$ nähern sich die Werte einander. Der Polarisationsversuch gibt einen nicht unbeträchtlichen Ausschlag, wobei vor und nach demselben der Widerstand sich nicht weiter ändert. 
Demnach zeigt der Quarz auch bei einer hohen Temperatur, bei welcher den Widerständen nach die die sekundäre elektrolytische Leitfähigkeit der niederen Temperaturen hervorrufenden Stoffe nicht mehr wirksam sind, Polarisation, welche darauf hindeutet, daß doch der Quarzsubstanz, wenn auch in geringem Maße, elektrolytische Leitfähigkeit bei hohen Temperaturen nicht fremd ist.

Der Versuch bei $1280^{\circ}$ ergibt einen großen Anfangsausschlag von $54 \mathrm{~mm}$, entsprechend $0.115 \mathrm{~m} \mathrm{~A}$. Zieht man den konstant bleibenden Ausschlag von $5 \mathrm{~mm}$ als Thermostrom ab, so verbleiben $i=0.104 \mathrm{~m} \mathrm{~A}$, was einer Spannung von 0.27 Volt entspräche. Der Ladungsstrom war $2.0 \mathrm{~m} \mathrm{~A}$, also bedeutend größer als bei der Temperatur von $1230^{\circ}$, der Widerstand $2580 \mathrm{Ohm}$, gegenüber 4180 bei der letztgenannten Temperatur.

\section{Quarz II.}

\begin{tabular}{|c|c|c|c|}
\hline Zeit & Temperatur & $\begin{array}{l}\text { Widerstand } \\
\text { in } \mathrm{Ohm}\end{array}$ & \\
\hline $2^{\mathrm{h}} 35^{\mathrm{m}}$ & $945^{\circ} \mathrm{C}$ & 9600 & \\
\hline 305 & 1070 & 1690 & \\
\hline 310 & 1090 & 1410 & \\
\hline 324 & 1100 & 1210 & \\
\hline 347 & 1120 & 1030 & Erster Polarisationsversuch. \\
\hline $4 \quad 12$ & 1200 & 1080 & \\
\hline 415 & 1240 & 880 & \\
\hline 430 & 1270 & 666 & \\
\hline
\end{tabular}

Bei diesem Versuch sinkt der Widerstand regelmäßig mit der Temperatur; eine Erhöhung, die aber nur unbedeutend war, findet bei dem Polarisationsversuch statt, indem der Widerstand von $1030 \mathrm{Ohm}$ bei $1120^{\circ}$ sich auf 1080 bei $1200^{\circ}$ gehoben hat.

Eigentümlich ist der schon bei $945^{\circ}$ geringe Widerstand, der nicht der Quarzsubstanz entspricht, sondern auch hier auf Bëimengung schließen läßt. Die Polarisation ist trotzdem bis $1120^{\circ}$ eine geringe, entsprechend $0.074 \mathrm{~m} \mathrm{~A}$; auch hier dürfte 
es sich wohl nicht mehr um die besprochene sekundäre elektrolytische Leitfähigkeit handeln.

\section{Quarz III (parallel der Achse).}

(Fig. 6.)

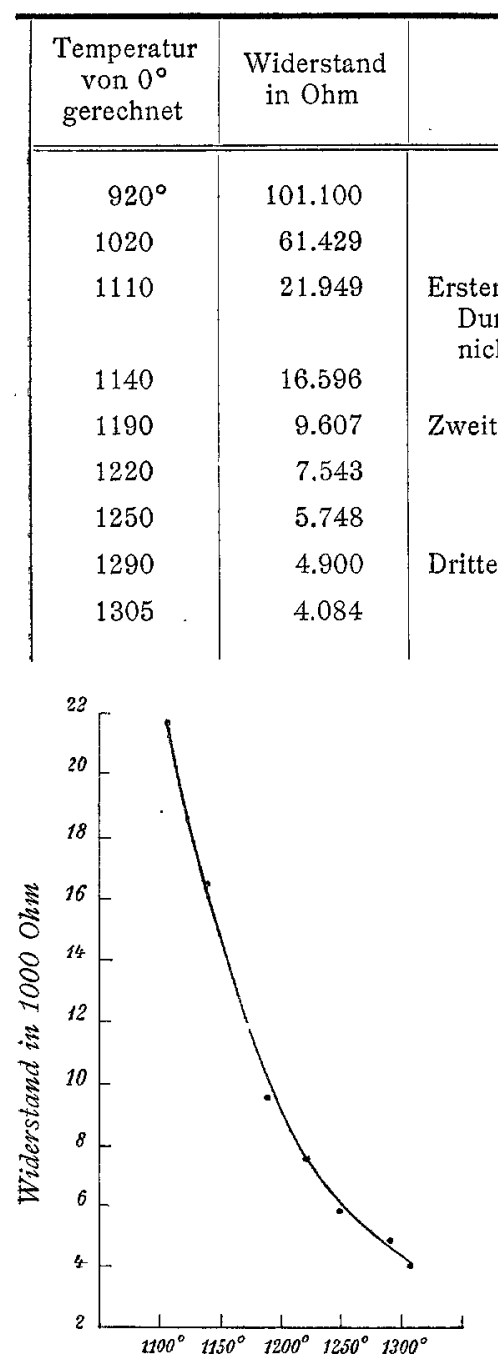

Fig. 6. Quarz III.

Bei $1190^{\circ}$ beträgt der Ausschlag nur $10 \mathrm{~mm}$, während bei $1290^{\circ}$ zirka $16 \mathrm{~mm}$ Ausschlag gemessen werden. Die Polarisation ist gering, da in diesen Beträgen auch der Thermostrom enthalten ist.

Dieser Quarz zeigt ganz bedeutende Unterschiede gegenüber dem früheren, die nicht auf Beobachtungsfehlern beruhen können. Offenbar ist hier ein Quarz vorgelegen, der frei von Beimengungen an Natriumsilikat war, daher die hohen Widerstände und die sehr geringe Polarisationsspannung. Bei Quarzen parallel zur Achse tritt immer erst bei hoher Temperatur eine kleine Polari- 
sation bei noch hohen Widerständen auf und in dieser Hinsicht stimmt dann dieser Quarz mit dem früher untersuchten überein.

Dieser Quarz war parallel der Achse geschnitten, muß also ganz große Unterschiede zeigen, wie bereits früher ${ }^{1}$ bei solchen Quarzen gezeigt wurde. Den großen Widerständen entsprechend ist der Polarisationsausschlag, der also dieses Mal der Quarzsubstanz und nicht den Beimengungen zukommt, weit geringer. Die Zahlen sind nur wenig höher als bei den früher untersuchten, parallel der Achse geschnittenen Quarzplatten. Ich verweise auf die früheren Ausführungen.

\section{Rauchquarz $A$.}

(Fig. 7.)

\begin{tabular}{|c|c|c|c|c|c|}
\hline Zeit & $\begin{array}{l}\text { Tempe- } \\
\text { ratur }\end{array}$ & $\begin{array}{c}\text { Wider- } \\
\text { stand }\end{array}$ & $\frac{1}{T}$ & $\log W$ & \\
\hline $8^{\mathrm{h}} 50^{\mathrm{m}}$ & 770 & 156.000 & $0.962 \times 10^{-3}$ & $5 \cdot 193$ & \\
\hline 915 & 900 & 47.000 & 0.855 & 4.672 & . \\
\hline 935 & 1020 & 23.000 & 0.775 & $4 \cdot 362$ & \\
\hline 950 & 1070 & 12.000 & 0.746 & 4.079 & \\
\hline 955 & 1100 & 10.000 & 0.727 & $4 \cdot 000$ & $\begin{array}{l}\text { Ladung mit Straßen- } \\
\text { strom. }\end{array}$ \\
\hline 1015 & 1130 & 8.200 & 0.714 & $3 \cdot 914$ & \\
\hline 1037 & 1200 & 3.600 & 0.680 & $3 \cdot 556$ & \\
\hline 1042 & 1200 & 2.270 & $0 \cdot 680$ & $3 \cdot 356$ & \\
\hline 1050 & 1200 & 1.870 & 0.680 & $3 \cdot 272$ & $\begin{array}{l}\text { Ladung mit Straßen- } \\
\text { strom. }\end{array}$ \\
\hline 1110 & 1210 & 2.220 & 0.676 & $3 \cdot 346$ & $\begin{array}{c}\text { Ladung mit Straßen- } \\
\text { strom. }\end{array}$ \\
\hline 1115 & 1250 & 1.300 & 0.658 & $3 \cdot 114$ & \\
\hline 1130 & 1300 & 1.080 & 0.637 & $3 \cdot 033$ & \\
\hline 1135 & 1305 & 960 & 0.635 & $2 \cdot 982$ & \\
\hline
\end{tabular}

Bei der ersten Polarisationsmessung war die Temperatur während des Ladens nicht konstant geblieben, so daß diese Messung nicht gut verwertet werden kann; der Ausschlag war bei $1105^{\circ}$ bis $1130^{\circ}$ enorm gro $\beta$ und entspricht einem Polarisationsstrom von $1.171 \mathrm{~mA}$.

1 Leitfähigkeit fester Silikate, 1. c., p. 20. 
Bei $1200^{\circ}$ war der Widerstand $1870 \Omega$, die Ladung erfolgte hier mit dem Straßenstrom und dauerte 5 Minuten. Es gingen anfangs $2 m \mathrm{~A}$ durch, welche nach 5 Minuten auf.1.1 $m \mathrm{~A}$

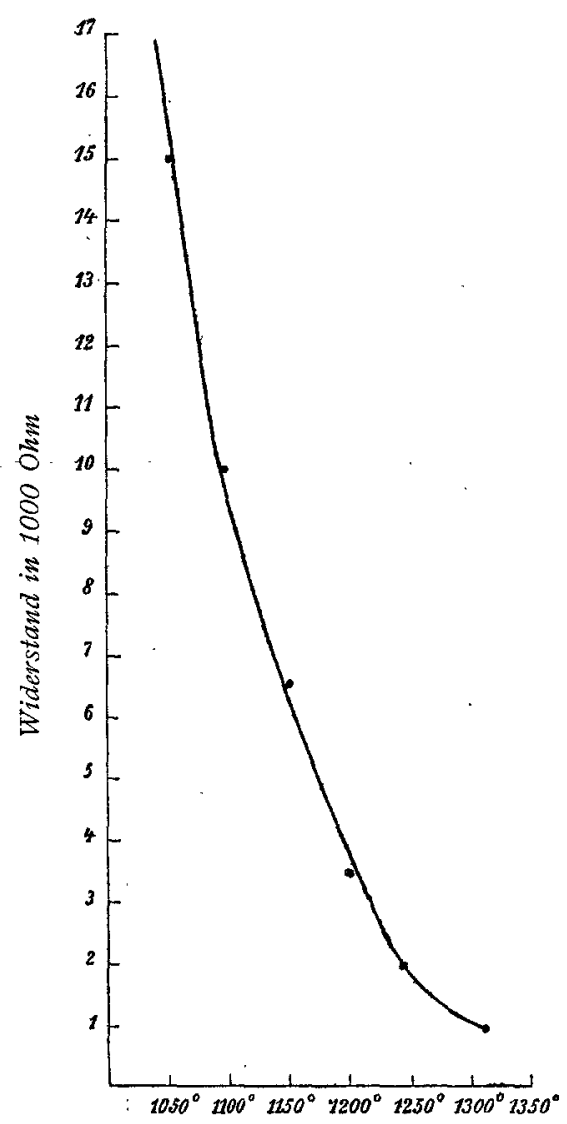

Fig. 7. Rauchquarz $A$.

abfielen. Auch hier war der Ausschlag an dem Spiegelgalvanometer groß, so daß der Zeiger über die Skala hindurchging. Nach 1 Minute waren noch $105 \mathrm{~mm}$ Ausschlag sichtbar, eine genaue Messung war daher nicht möglich; nähme man letztere Zahl, so erhielte man $0.905 \mathrm{~m}$ A und eine Spannung von 1.69 Volt; aber die elektromotorische Kraft war viel größer. Wahrscheinlich haben wir es mit sekundärer Leitfähigkeit zu tun. 


\section{Rauchquarz $B$.}

(Fig. 8.)

\begin{tabular}{|c|r|l|}
\hline Temperatur & $\begin{array}{r}\text { Widerstand } \\
\text { in Ohm }\end{array}$ & \\
\hline \hline $850^{\circ} \mathrm{C}$ & 12.700 & \\
890 & 13.530 & \\
900 & 18.170 & Wahrscheinlich rührt diese Erhöhung von \\
Ubergangswiderständen her. \\
950 & 15.000 & \\
1000 & 9.800 & \\
10501 & 5.920 & Ladung mit dem Straßenstrom, nach der Ent- \\
1120 & 3.790 & ladung betrug der Widerstand 6660. \\
1150 & 1.700 & \\
1210 & 850 & \\
1250 & 700 & Nach dem Laden mit dem Straßenstrom betrug \\
1290 & 1.010 & der Widerstand 1570. \\
1300 & 960 &
\end{tabular}

Bei diesem Rauchquarz sind wie bei dem auf p. 525 erwähnten geringe Widerstände zu verzeichnen. Die Kurve verläuft sehr regelmäßig; bei der Ladung mit dem Akkumulator wird eine Erhöhung des Widerstandes beobachtet; die Polarisation ist schon bei $1050^{\circ}$ merklich. Diese Kurve nähert sich der des Quarzes I, weicht aber von jener des Rauchquarzes $A$ erheblich ab. Die Kurve des ersten Rauchquarzes ist eine andere, die Widerstände sind viel höher als bei den anderen Quarzen und erst von $1000^{\circ}$ an nähern sich die Zahlen.

Ein Polarisationsversuch mit dem Rauchquarz $B$ wurde bei $1250^{\circ}$ ausgeführt; Ladungszeit mit einem Akkumulator $5 \mathrm{Mi}$ nuten; der Ladungsstrom betrug $2 m \mathrm{~A}$, welcher nach 5 Minuten verschwunden war. Die Entladung ergab einen Ausschlag von $54 \mathrm{~mm}$, wovon $5 \mathrm{~mm}$ auf Rechnung des Thermostromes kommen; dem entspricht ein Polarisationsstrom von $0.104 m$ A,

1 Auffallend ist die Erhöhung des Widerstandes durch das Laden; es muß hier an chemische Veränderung, die wahrscheinlich die Einschlüsse im Natriumsilikat betreffen, gedacht werden. 
beziehungsweise 0.49 Volt; er ist also ganz erheblich und überdies bei einer Temperatur, bei welcher wenigstens ein Teil der Beimengung ihre Wirkung verloren haben mußte.

Die Quarze verhalten sich demnach sehr verschieden; ihre elektrolytische Leitung ist zum größten Teil auf Beimengungen

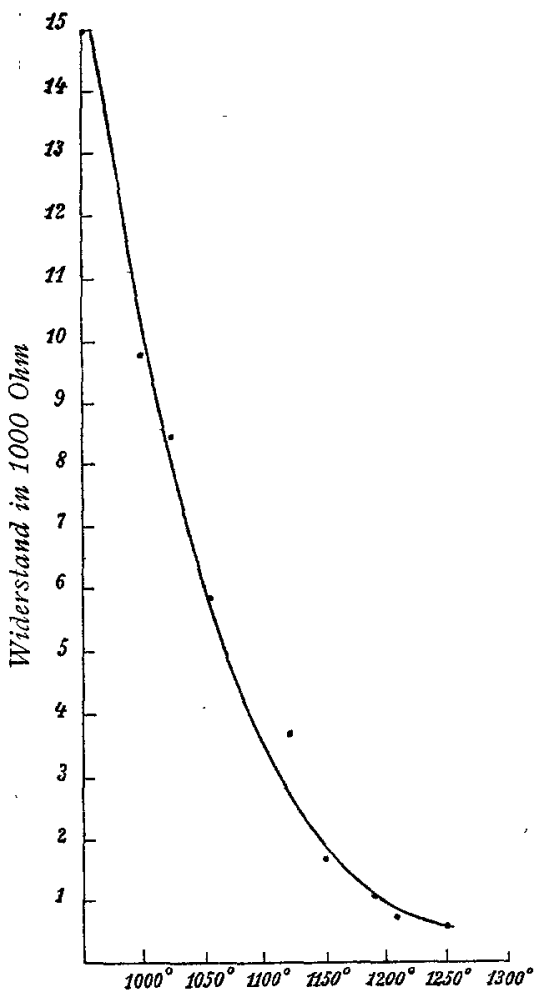

Fig. 8. Rauchquarz $B$. von Flüssigkeit zurückzuführen; je nach der vorhandenen Menge dieser und ferner je nach der Verteilungsart ist die Leitfähigkeit und auch die Spannung des Polarisationsstromes verschieden. ${ }^{1}$ Wo reiner Quarz vorliegt, ist der Widerstand ein großer und umgekehrt, wo der Widerstand bei verhältnismäßig geringer Temperatur klein ist, liegen Beimengungen vor; dann ist auch der Polarisationsstrom sehr merklich. Aber auch bei hohen Widerständen (p. 513) ist ein kleiner Betrag dafür ermittelt, der wie bei Quarzen parallel der Achse nicht sekundärer Leitfähigkeit zuzuschreiben ist.

\section{Saphir $\left(\mathrm{Al}_{2} \mathrm{O}_{3}\right)$.}

Es wurde eine sehr reine Platte von weißem Saphir aus Ceylon verwendet, in welcher unter dem Mikroskop keine Einschlüsse zu bemerken waren. Die Krystallplatte war senkrecht zur optischen Achse geschnitten und auffallend durchsichtig und rein. $\mathrm{Zu}$ beachten ist auch ein nach Erhitzung der 
Platte auf $1330^{\circ}$ unternommener Färbungsversuch mit Radiumstrahlen. Wie bekannt, ${ }^{1}$ wird auch weißer Saphir durch diese Strahlung gelbbraun gefärbt; der auf obige Temperatur erhitzte Saphir wird nun gerade wie der ursprüngliche gelbbraun gefärbt, die färbende Substanz scheint also in der Substanz des Saphirs selbst zu liegen und nicht beigemengt $z u$ sein; beim Erhitzen schwindet die Färbung. Ein braungelber Saphir gab ungefähr dieselben Werte für die Leitfähigkeit wie der ungefärbte, was wohl dem Umstande zuzuschreiben ist, daß die Färbung schon viel früher verschwindet, als Leitfähigkeit wahrnehmbar ist, die ja erst bei zirka $800^{\circ}$ meßbar wurde.

Die folgenden Werte der ersten Erhitzung wurden mit dem ungefärbten Stein erhalten, doch ist der Umstand belanglos wegen der Entfärbung in der Hitze.

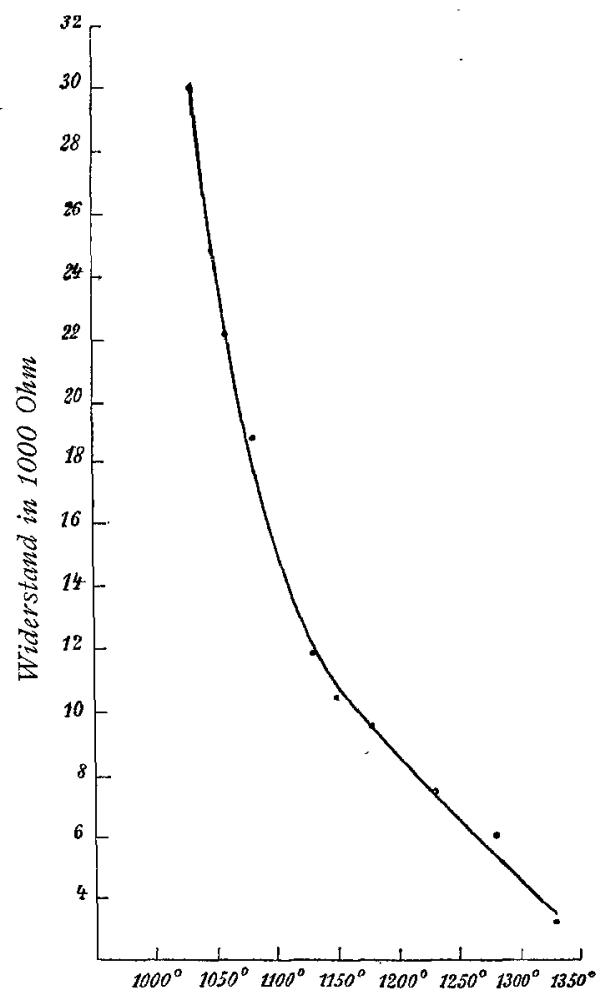

Fig. 9. Saphir.

Wie aus den beiden Zahlenreihen ersichtlich ist, sind die Werte der ersten Erhitzung anfangs größer, wie dies immer bei der Versuchsanordnung mit Krystallplatten der Fall ist; bei $1000^{\circ}$ sind sie nicht sehr verschieden, wenn man berücksichtigt, daß ein Unterschied von $10^{\circ}$ große Widerstandsdifferenzen mit sich bringt.

1 C. Doelt er, Das Radium und die Farben. Dresden 1910, p. 62. 
Saphir.

\begin{tabular}{|c|c|c|c|c|}
\hline Zeit & Temperatur & $\begin{array}{c}\text { Widerstand } \\
\text { in Ohm }\end{array}$ & $\begin{array}{c}\frac{1}{T} \\
\text { in absoluter } \\
\text { Zählung }\end{array}$ & $\log W$ \\
\hline
\end{tabular}

Erste Erhitzung (Fig. 9.)

\begin{tabular}{|l|c|r|r|r|}
\hline $3^{\mathrm{h}} 36^{\mathrm{m}}$ & $830^{\circ}$ & 275.000 & $0 \cdot 000909$ & $5 \cdot 4393$ \\
345 & 930 & 79.300 & 883 & 4.8993 \\
400 & 1030 & 29.200 & 769 & $4 \cdot 4654$ \\
& $1080^{1}$ & 18.600 & 741 & 4.2695 \\
& 1130 & 11.700 & 714 & 4.0682 \\
416 & 1180 & 9.600 & 687 & 3.9823 \\
455 & 1230 & 7.500 & 667 & 3.8751 \\
520 & 1280 & 6.200 & 645 & 3.7924 \\
530 & $1330^{2}$ & 3.300 & 625 & 3.5185 \\
\hline
\end{tabular}

1 Polarisationsversuch.

2 Polarisationsversuch; der Widerstand war nach demselben nicht geändert.

Zweite Erhitzung (Fig. 10)

\begin{tabular}{|r|r|r|r|r|}
\hline \multirow{4}{*}{420} & $830^{\circ}$ & 140.000 & $0 \cdot 000909$ & $5 \cdot 3802$ \\
880 & 115.000 & 870 & $5 \cdot 0607$ \\
930 & 40.000 & 833 & $4 \cdot 6021$ \\
& 1010 & 25.000 & 781 & $4 \cdot 3979$ \\
& 1080 & 13.800 & 741 & $4 \cdot 1399$ \\
& 1130 & 10.200 & 714 & $4 \cdot 0086$ \\
1180 & 7.500 & 690 & $3 \cdot 8751$ \\
& 1230 & 5.600 & 667 & $3 \cdot 7482$ \\
& 12803 & 11.300 & 645 & $4 \cdot 0531$ \\
& 1290 & 13.800 & 642 & $4 \cdot 1399$ \\
& & & &
\end{tabular}

3 Bei $1200^{\circ}$ wurde ein Polarisationsversuch ausgefürt, ein zweiter bei $1280^{\circ}$; hierbei ergab sich das merkwürdige Resultat, daß der nach der Entladung gemessene Widerstand größer war wie früher vor der Entladung. 
Saphir zeigt bei niederen Temperaturen überaus hohe Widerstände, erst bei $1050^{\circ}$ ungefähr fallen sie sehr bedeutend und bei $1200^{\circ}$ haben wir nur einige tausend $\mathrm{Ohm}$.

Ganz auffallend groß ist hier die Polarisationsspannung, wenn man sie mit den früher behandelten Krystallen vergleicht.

Auch war hier nachher Rauheit der Elektroden zu beobachten; die eine Seite der Saphirplatte war rauh und wie geätzt, mit kleinen Vertiefungen.

Optische Veränderungen konnten nach dem Erhitzen an dem Saphir, soweit es sich um sein Interferenzbild im Konoskop handelt, nicht beobachtet werden.

Polarisation. Mit dieser Saphirplatte wurde bei der ersten Erhitzung bei $1180^{\circ}$ ein Polarisationsversuch unternommen, der einen bedeutenden Ausschlag gab; die erste Messung dagegen gab nur einen sehr geringfügigen Ausschlag. Bei $1180^{\circ}$ war der Widerstand $9600 \mathrm{Ohm}$, der Ladungsstrom, welcher von einem Akkumulator

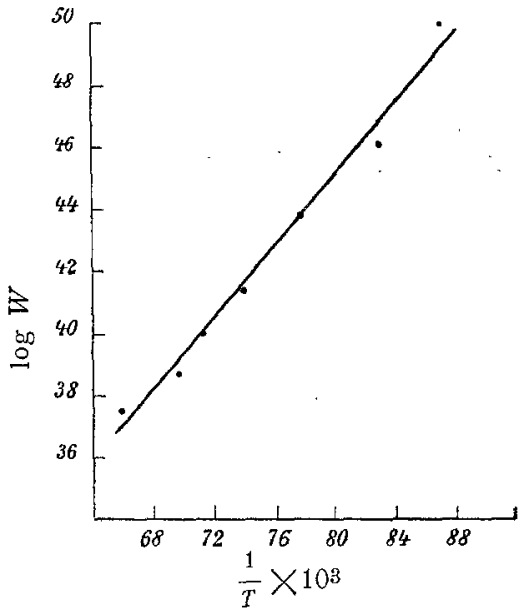

Fig. 10 . geliefert wurde, war $0.1 \mathrm{~m} \mathrm{~A}$, der Entladungsstrom betrug $2.5 m$, welchen 0.24 Volt entsprechen.

Bei $1280^{\circ}$ war der Ladestrom $0.5 \mathrm{~m} \mathrm{~A}$; für den Polarisationsstrom erhält man $i=0.066 \mathrm{~m} \mathrm{~A}$, beziehungsweise $0.41 \mathrm{Volt}$.

Bei $1330^{\circ}$ (Versuch 2) war der Ladungsstrom $1 \mathrm{~m}$ A, der durch die Platte ging; der Widerstand ist 2300 Ohm. Der Ausschlag ist sehr groß, $54 \mathrm{~m}$ A, entsprechend einem Polarisationsstrom von $0.115 \mathrm{~m} \cdot \mathrm{A}$, beziehungsweise 0.28 Volt.

Wir wissen, daß der Korund $\left(\mathrm{Al}_{2} \mathrm{O}_{3}\right)$ im Schmelzzustand stark elektrolytisch leitet, und beruht ja die Aluminiumfabrikation auf der Elektrolyse der Tonerde. Der Schmelzpunkt des Saphirs ist sehr hoch, zirka $1750^{\circ}$ bis $1800^{\circ}$, so daß bei meinen Versuchen noch $400^{\circ}$ mindestens zum Schmelzpunkt fehlten; 
irgendein Grund zu einer sekundären Ursache der starken Polarisationserscheinungen liegt hier nicht vor, denn, wenn etwa eine ähnliche Erscheinung wie bei Quarz vorläge, so müßten auch ähnliche Verhältnisse wie bei diesem zur Erscheinung kommen, nämlich starke Leitfähigkeit bei niederer Temperatur und verminderte Leitfähigkeit bei hoher Temperatur. Es ist demnach sehr wahrscheinlich, daß bei Saphir Elektrolyse schon im festen Zustande eintritt, um so mehr als die Oberfläche im Kontakt mit den Elektroden angegriffen war.

Magnetit von Pfitsch.

\begin{tabular}{|c|l||c|c||c|c|}
\hline Temperatur & $\begin{array}{c}\text { Widerstand } \\
\text { in Ohm }\end{array}$ & Temperatur & $\begin{array}{c}\text { Widerstand } \\
\text { in Ohm }\end{array}$ & Temperatur & $\begin{array}{c}\text { Widerstand } \\
\text { in Ohm }\end{array}$ \\
\hline $375^{\circ} \mathrm{C}$ & 0.64 & $750^{\circ}$ & 0.786 & $1100^{\circ}$ & 0.666 \\
450 & 0.70 & 805 & 0.712 & 11501 & 0.650 \\
500 & 0.739 & 900 & 0.694 & 1175 & 0.639 \\
600 & 0.808 & 950 & 0.680 & 1200 & 0.639 \\
655 & 0.802 & 1000 & 0.678 & & \\
& & & & &
\end{tabular}

Zweite Erhitzung.

(Fig. 11.)

\begin{tabular}{|c|c|c|c|c|c|c|}
\hline Zeit & $\begin{array}{l}\text { Tempe- } \\
\text { ratur }\end{array}$ & $\begin{array}{l}\text { Wider- } \\
\text { stand } \\
\text { in } \mathrm{Ohm}\end{array}$ & & Zeit & $\begin{array}{l}\text { Tempe- } \\
\text { ratur }\end{array}$ & $\begin{array}{l}\text { Wider- } \\
\text { stand } \\
\text { in } \mathrm{Ohm}\end{array}$ \\
\hline $8^{\mathrm{h}} 05^{\mathrm{m}}$ & $15^{\circ}$ & $1 \cdot 198$ & \multirow{7}{*}{$\begin{array}{l}\text { Minimum } \\
\text { undeutlich }\end{array}$} & \multirow{7}{*}{$\begin{array}{ll}10^{\mathrm{h}} & 50^{\mathrm{m}} \\
11 & 00 \\
11 & 15 \\
11 & 27 \\
11 & 50 \\
12 & 00\end{array}$} & $700^{\circ}$ & $0 \cdot 754$ \\
\hline 820 & 100 & 0.945 & & & 800 & 0.751 \\
\hline 830 & 200 & 0.887 & & & 900 & $0 \cdot 751$ \\
\hline 855 & 300 & 0.835 & & & 1000 & 0.712 \\
\hline 935 & 400 & 0.818 & & & 1100 & 0.694 \\
\hline 1000 & 500 & 0.739 & & & 1150 & 0.694 \\
\hline 1020 & 600 & $0 \cdot 754$ & & & & \\
\hline
\end{tabular}

Magneteisen ist ein Körper mit metallischer Leitung, der schon bei der Temperatur von $15^{\circ}$ große Leiffähigkeit besitzt, 
die sich bei Temperaturerhöhung nur noch wenig verändert. Zwischen $15^{\circ}$ und $1170^{\circ}$ ist der Unterschied zirka $1 / 2$ Ohm, so daß der Widerstand bei ersterer Temperatur nicht gan $z$ doppelt so hoch ist wie bei $1170^{\circ}$. Das Magneteisen verändert sich jedoch bei hohen Temperaturen und hat nach dem Herausnehmen aus dem Ofen eine grünlichschwarze Farbe angenommen.

Polarisation ist nicht $z \mathrm{u}$ bemerken; jedenfalls ist hier Elektronenleitung vorhanden. Einen Minimalpunkt habe ich in der Kurve nicht wahrgenommen, doch sind genaue Messungen mit Gleichstrom hier nötig; denn wie aus meinen Zahlen

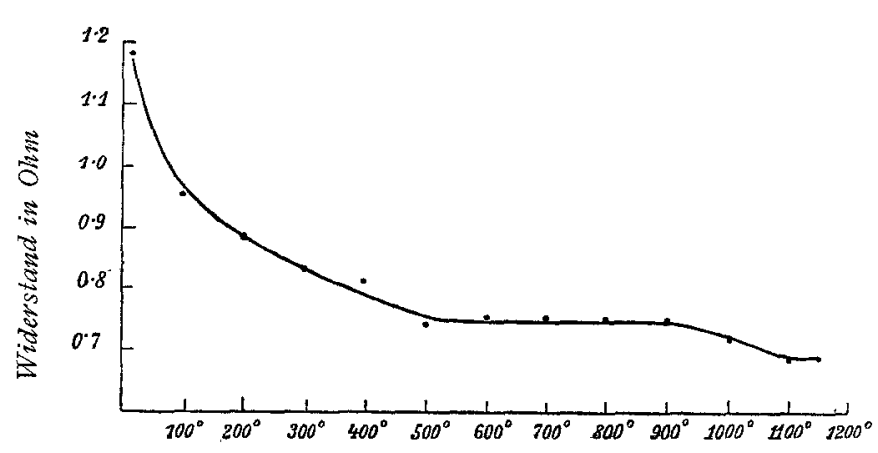

Fig. 11. Magneteisen.

hervorgeht, sind die Unterschiede der gemessenen Widerstände so gering, daß die Kurve keinen Anspruch auf Genauigkeit machen kann.

Beyeringk hat nach Wiedemann eine Kurve der Leitfähigkeit des Magnetits bis $130^{\circ}$ gegeben. Die Kurve ist der meinigen ähnlich, die Werte etwas geringer. Auch Haßlinger untersuchte künstliches Eisenoxyduloxyd und erhielt eine analoge Kurve.

Den Magnetit hat auch Königsberger, jedoch bei niedereren Temperaturen untersucht; er fand einen Minimalpunkt. Seine Messungen dürften bei niederen Temperaturen genauer ausgefallen sein wie die meinen, da, wie erwähnt, wegen der Übergangswiderstände bei niederen Temperaturen die Messungen nach meiner Methode nicht so genau sind. Auch wäre hier 
die Untersuchung besser mit einem längeren Stäbchen aus: gefallen.

\section{Zinkblende $(\mathrm{ZnS})$.}

Eine gelbe spanische Zinkblende zeigte bei $400^{\circ}$ noch keine Leitfähigkeit. Die vergoldete Platte war in der Presse zwischen Platinelektroden eingespannt worden. Über $420^{\circ} \mathrm{zu}$ erhitzen, war wegen der beginnenden Zersetzung nicht möglich.

\section{Chrysoberyll $\left(\mathrm{Be}_{2} \mathrm{O}_{4}\right)$.}

Der verwendete Chrysoberyll stammt von Ceylon; er war gelblich. Die Platte ist parallel der Spaltrichtung geschliffen.

\section{Chrysoberyll, erste Erhitzung.}

(Fig. 12.)

\begin{tabular}{|c|c|c|c|}
\hline $\begin{array}{c}T \\
\text { von } 0^{\circ} \mathrm{C} . \\
\text { gerechnet }\end{array}$ & $\begin{array}{c}\text { Widerstand } \\
\text { in Ohm }\end{array}$ & $\begin{array}{c}\frac{1}{T} \\
\text { in absoluter } \\
\text { Zählung }\end{array}$ & $\log W$ \\
\hline \hline $800^{\circ}$ & 41.000 & $0.935 \times 10^{-3}$ & $4 \cdot 612$ \\
900 & 37.600 & 0.855 & 4.575 \\
1000 & 33.290 & 0.787 & 4.522 \\
1100 & 20.860 & 0.730 & 4.319 \\
1200 & 16.450 & 0.680 & 4.216 \\
1250 & 13.420 & 0.658 & 4.128 \\
1310 & 8.600 & 0.633 & 3.982 \\
1370 & 8.520 & 0.610 & 3.930 \\
& & &
\end{tabular}

Die Polarisationsversuche bei Chrysoberyll, bei $1200^{\circ} \mathrm{mit}$ dem Straßenstrom durchgeführt, ergaben einen Ausschlag von $11.4 \mathrm{~mm}$, welcher nach 5 Minuten auf $10.7 \mathrm{~mm}$, also fast gar nicht abfiel; es liegt also kein Polarisationsstrom vor. Auch bei $1250^{\circ}$ war fast nur Thermostrom vorhanden.

Bei der ersten Erhitzung war bei $1370^{\circ}$ ein Polarisationsversuch unternommen worden. Die Ladezeit war 15 Minuten, also größer als bei anderen Versuchen, und der Ladestrom war 
anfangs bedeutend, $31 \mathrm{~m} \mathrm{~A}$, und sank zum Schluß auf $5 \mathrm{~m}$ A herab. Die Entladung ergab einen anfänglichen Ausschlag von $12.5 \mathrm{~mm}$, entsprechend $1.598 \mathrm{~mA}$, doch war der gröBere Teil auf Rechnung von Thermostrom $z u$ setzen. Für den Polarisationsstrom verbleiben nur $0.32 \mathrm{~m}$ A.

Da der Ausschlag merkwürdigerweise nicht oder vielmehr um nur. $5 \mathrm{~mm}$ herabsank, so daß weitaus der größte Teil hier nicht auf Rechnung des Polarisationsstromes kommt, so dürften hier Peltier'sche Ströme neben gewöhnlichen Thermoströmen vorliegen; nur ein geringer Polarisationsstrom ist bei $1370^{\circ}$

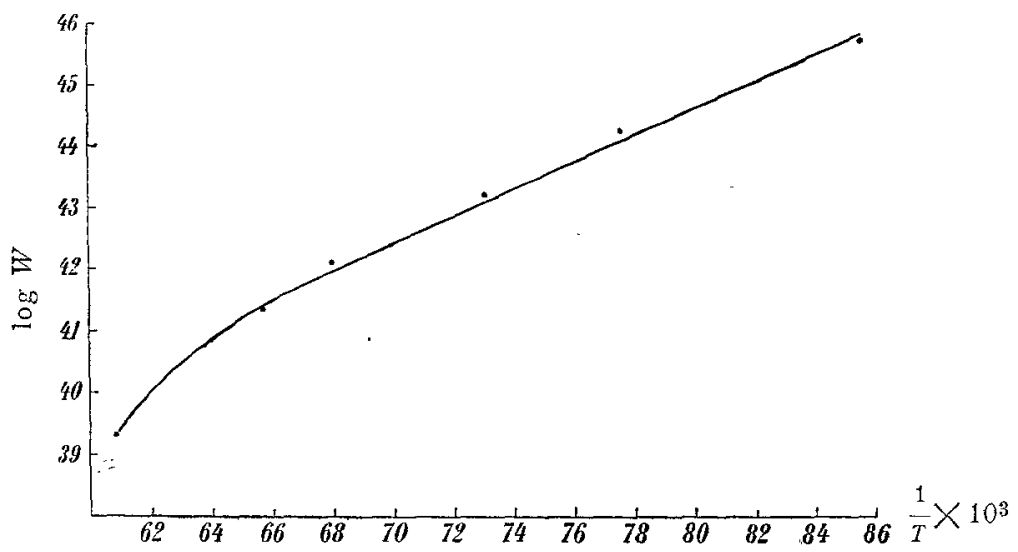

Fig. 12. Chrysoberyll.

vorhanden. Allerdings ist der Schmelzpunkt des Chrysoberylls ein außerordentlich hoher, so daß jene Temperatur noch weit unter dem Schmelzpunkt liegt.

Es war zu erwarten, daß Salze wie Chrysoberyll und auch Magneteisen elektrolytische Leitfähigkeit zeigen, was sich nicht bestätigt; allerdings ist ja die Salznatur mehr hypothetisch, z. B. bei Magneteisen $\mathrm{FeO} . \mathrm{Fe}_{2} \mathrm{O}_{3}$.

\section{Granat, Almandin.}

Zur Untersuchung gelangte ein orientalischer Almandin; die Platte zeigt schön hellrote Färbung, keine Einschlüsse, jedoch einige kleinere Sprünge. Bei Granat ist leider mit dem 
Umstande zu rechnen, daß derselbe infolge seines Eisengehaltes sich zersetzt.

\section{Granat, Almandin.}

(Fig. 12.)

\begin{tabular}{|c|c|c|c|c|c|}
\hline Zeit & Temperatur & $\begin{array}{c}\text { Widerstand } \\
\text { in Ohm }\end{array}$ & Zeit & Temperatur & $\begin{array}{l}\text { Widerstand } \\
\text { in Ohm }\end{array}$ \\
\hline $9^{\mathrm{h}} \quad 40^{\mathrm{m}}$ & $610^{\circ}$ & 9.230 & $10^{\mathrm{b}} \quad 55^{\mathrm{m}}$ & $850^{\circ}$ & 790 \\
\hline $10 \quad 03$ & 640 & 4.590 & 1106 & 900 & 970 \\
\hline $10 \quad 15$ & 700 & 2.920 & $11 \quad 15$ & 950 & 900 \\
\hline $10 \quad 28$ & 750 & 2.070 & 1126 & 1000 & 500 \\
\hline $10 \quad 45$ & 800 & 820 & 1135 & 1015 & 270 \\
\hline
\end{tabular}

Der Verlauf der Kurve ist bei $900^{\circ}$ unregelmäßig; es dürfte dies entweder auf Übergangswiderstände zurückzuführen sein oder wahrscheinlicher auf eine bei dieser Temperatur ein-

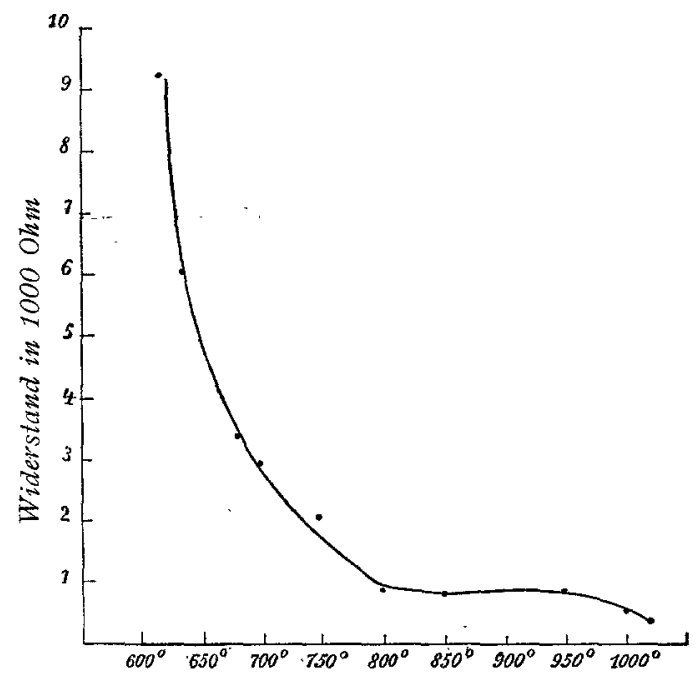

Fig. 13. Granat.

getretene Zersetzung des eisenreichen Granates. Bei dem Herausnehmen des Granates zeigt sich in der Tat, daß der Granat, der früher rosenfarben war, dunkelschwarzbraun und trübe geworden war. Es wurde von diesem Granat ein Bruchstück unter 
dem Krystallisationsmikroskop beobachtet und es ergab sich Veränderung gegen $900^{\circ}$ bis $950^{\circ}$; der Schmelzpunkt liegt zwischen $1150^{\circ}$ bis $1250^{\circ}$, der Schmelzbeginn ist $1150^{\circ}$, doch der Schmelzprozeß geht nur äußerst langsam vor sich, wie ja bei den meisten Tonerdesilikaten.

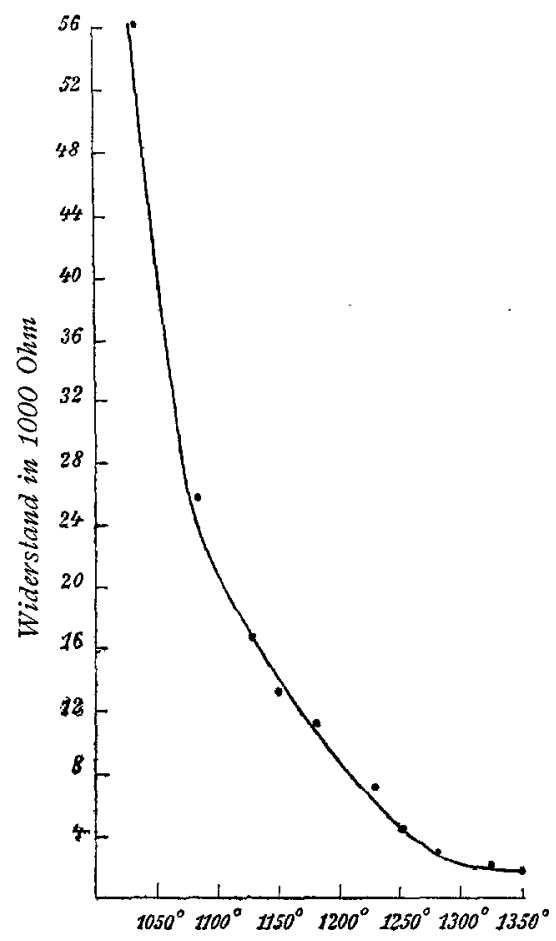

Fig. 14. Topas.

Polarisationsversuche wurden bei $635^{\circ}$ und $1000^{\circ}$ ausgeführt, wobei die Ladung mit einem Akkumulator erfolgte. Der erste Versuch war erfolglos, der zweite ergab einen kleinen Ausschlag von $10 \mathrm{~mm}$, also sehr unbedeutend. Da der Granat überdies seine Zusammensetzung verändert hatte, wurde die Erhitzung nicht weiter fortgesetzt.

\section{Topas.}

Es wurde ein farbloser sibirischer Topas parallel der Basis verwendet; die optische Untersuchung ergab den gewöhnlichen 
großen Achsenwinkel. Die erste Erhitzung erfolgte bis $1000^{\circ}$; bei dieser Temperatur war ein Widerstand von zirka $90.000 \mathrm{Ohm}$ meßbar. Die nach der Abkühlung vorgenommene Untersuchung ergab keine Veränderung des optischen Verhaltens und speziell des Achsenwinkels. Die zweite Erhitzung ergab folgende Werte:

\section{Topas.}

(Fig. 14.)

\begin{tabular}{|c|c|c|c|c|c|}
\hline \multicolumn{2}{|c|}{ Zeit } & $\begin{array}{c}\text { Temperater } \\
\text { von } 0^{\circ} \\
\text { gerechnet }\end{array}$ & $\begin{array}{l}\text { Widerstand } \\
\text { in Ohm }\end{array}$ & $\frac{1}{T} \underset{\substack{\text { in absoluter } \\
\text { Zählung }}}{ }$ & $\log W$ \\
\hline & $20^{\mathrm{na}}$ & 830 & 323.000 & $0^{.909 \times 10^{-3}}$ & $5 \cdot 5092$ \\
\hline \multirow[t]{2}{*}{3} & 50 & 880 & 190.000 & $0.870 \times 10^{-3}$ & $5 \cdot 2788$ \\
\hline & & 940 & 156.000 & $0.826 \times 10^{-3}$ & $5 \cdot 1931$ \\
\hline \multirow[t]{2}{*}{4} & 05 & 980 & 116.000 & $0.800 \times 10^{-3}$ & $5 \cdot 0645$ \\
\hline & & 1030 & 56.000 & $0.769 \times 10^{-3}$ & $4 \cdot 7482$ \\
\hline 4 & 25 & 1130 & 16.300 & $0.714 \times 10^{-3}$ & $4 \cdot 2122$ \\
\hline 4 & 50 & 11801 & 11.050 & $0.689 \times 10^{-3}$ & $4 \cdot 0434$ \\
\hline 5 & 15 & $1250^{2}$ & 4.080 & $0.658 \times 10^{-3}$ & $3 \cdot 6107$ \\
\hline 5 & 20 & 1280 & 3.100 & $0.645 \times 10^{-3}$ & $3 \cdot 4914$ \\
\hline & 31 & $1330^{3}$ & 2.070 & $0.625 \times 10^{-3}$ & $3 \cdot 3160$ \\
\hline & & & 2.000 & $0.617 \times 10^{-3}$ & $3 \cdot 3010$ \\
\hline $\operatorname{dem}$ & $\begin{array}{r}1 \mathrm{Be} \\
2 \mathrm{Be} \\
\text { Versu } \\
3 \mathrm{Dr}\end{array}$ & $\begin{array}{l}0^{\circ} \text { erster Po } \\
0^{\circ} \text { zweiter } \mathrm{F} \\
\text { on } 4080 \text { auf } \\
\text { Polarisations }\end{array}$ & $\begin{array}{l}\text { risationsversu } \\
\text { larisationsvers } \\
700 \text { gefallen b } \\
\text { ersuch. }\end{array}$ & $\begin{array}{l}\text { ch. Der Widers } \\
\text { i Konstanz der }\end{array}$ & $\begin{array}{l}\text { war nach } \\
\text { peratur. }\end{array}$ \\
\hline
\end{tabular}

Der Ausschlag bei $1180^{\circ}$ betrug nur $5 \mathrm{~mm}$. Bei $1250^{\circ}$ war der Ladestrom, den ein Akkumulator lieferte, $0.95 \mathrm{~m} \mathrm{~A}$; der Ausschlag betrug $17 \mathrm{~mm}$, welcher nach $1 \frac{1}{2}$ Minuten zurückging; es entspräche dies einem Strom von $0.036 \mathrm{~m} \mathrm{~A}$, beziehungsweise $0 \cdot 13$ Volt.

Bei $1330^{\circ}$ war der Ladungsstrom $1.8 m \mathrm{~A}$, der Ausschlag $47 \mathrm{~mm}$, entsprechend $0.1 \mathrm{~m} \mathrm{~A}$, beziehungsweise $0.21 \mathrm{Volt}$, wobei sich der merkwürdige Umstand ereignete, daß nach 
$2 \frac{1}{2}$ Minuten der Strom auf Null abgefallen und nach 3 Minuten ein Ausschlag im entgegengesetzten Sinne von $4 \mathrm{~mm}$ zu beobachten war, vielleicht infolge eines Peltierstromes. Es darf aber nicht vergessen werden, daß schon bei $1350^{\circ}$ die Zersetzung des Topases beginnt und daß chemische Prozesse mitspielen;

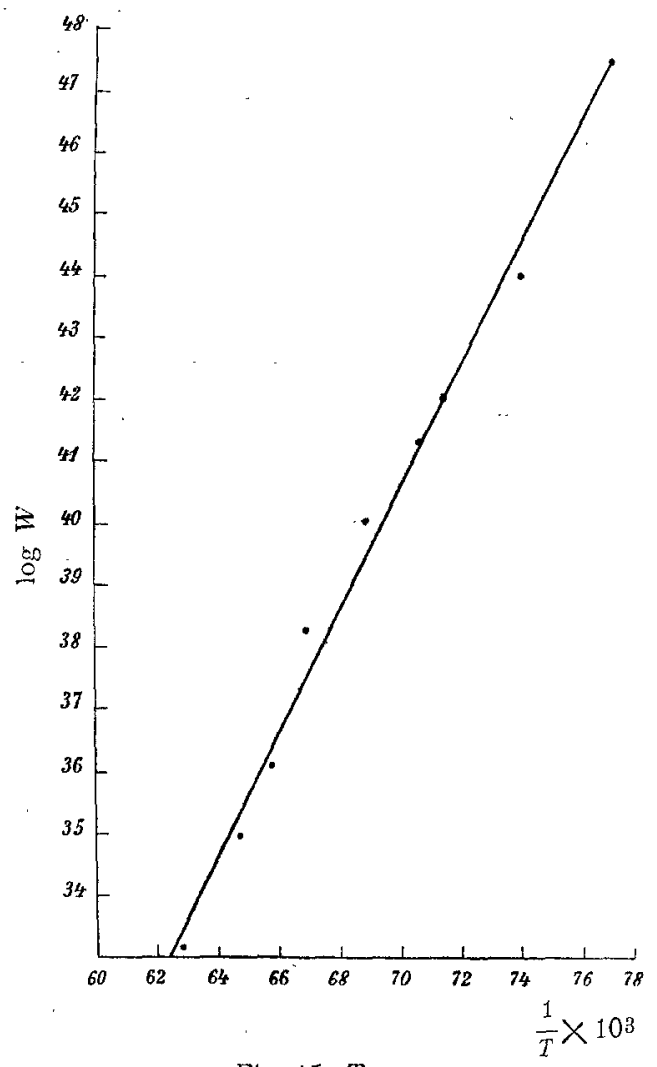

Fig. 15. Topas.

es ist also möglich, daß durch das Laden der Platte die Zersetzung beschleunigt wird.

Der Topas verändert sich wie Granat bei höherer Temperatur; aus der Verbindung $\left(\mathrm{Al}_{2} \mathrm{SiO}_{5}\right)_{5} \cdot \mathrm{Al}_{2} \mathrm{SiF}_{10}$ oder $\mathrm{Al}_{12} \mathrm{Si}_{6} \mathrm{O}_{25} \mathrm{~F}_{10}$ wird das Fluor ausgetrieben, dabei ist der Topas bei zirka $1250^{\circ}$ trübe, undurchsichtig und milchwei $\beta,{ }^{1}$ während er früher

1 Dieser zersetzte Topas wird durch Radium nicht mehr verändert. 
farblos und durchsichtig ist. Der Umwandlungspunkt ließ sich aber nicht genau feststellen,

Die Widerstandskurve ist ziemlich regelmäßig; bei $1200^{\circ}$ wird der Widerstand gering und die Kurve verläuft dann fast horizontal.

Polarisation ist sicher vorhanden, denn nicht nur die Elektroden sind etwas rauh, auch die eine Seite der Krystallplatte zeigte ein rauhes und wie geätztes Aussehen; hier hat also wohl Transport von ponderabler Materie stattgefunden.

\section{Baryt.}

(Fig. 16 und 17.)

\begin{tabular}{|c|c|c|c|c|c|}
\hline \multicolumn{2}{|c|}{ Zeit } & $\begin{array}{c}\text { Temperatur } \\
\text { von } 0^{\circ} \\
\text { gezählt }\end{array}$ & $\begin{array}{l}\text { Widerstand } \\
\text { in } \mathrm{Ohm}\end{array}$ & $\begin{array}{l}\frac{1}{T} \\
\text { in absoluter } \\
\text { Zählung }\end{array}$ & $\log W$ \\
\hline \multirow{2}{*}{\multicolumn{2}{|c|}{$9^{\mathrm{h}} 55^{\mathrm{m}}$}} & $800^{\circ}$ & 190.000 & 0.000935 & $5 \cdot 2788$ \\
\hline & & 900 & 101.000 & 0.000855 & $5 \cdot 0043$ \\
\hline 10 & 33 & 1000 & 40.000 & 787 & $4 \cdot 6021$ \\
\hline 10 & 37 & 1050 & 27.700 & 757 & $4 \cdot 4425$ \\
\hline 10 & 52 & 11001 & 18.500 & 730 & $4 \cdot 2672$ \\
\hline 11 & 20 & 1150 & 12.200 & 704 & $4 \cdot 0864$ \\
\hline 11 & 27 & 1200 & 9.000 & 680 & $3 \cdot 9542$ \\
\hline 11 & 38 & $1210^{2}$ & 8.500 & 676 & $3 \cdot 9294$ \\
\hline 11 & 50 & 1250 & 7.000 & 658 & $3 \cdot 8451$ \\
\hline 11 & 58 & $1300^{3}$ & 5.080 & 637 & $3 \cdot 7059$ \\
\hline 12 & 30 & $1350^{4}$ & 3.200 & 617 & $3 \cdot 5052$ \\
\hline $\begin{array}{l}\text { erhöh } \\
8500 \\
\text { auf } 4 \\
\text { währe } \\
\text { gegen }\end{array}$ & $\begin{array}{l}1 \text { Ers } \\
2 \mathrm{Zw} \\
\text { t und } \\
\text { Ohm, } \\
3 \mathrm{Bei} \\
380 \mathrm{O} \\
4 \mathrm{Bei} \\
\text { end de } \\
3200\end{array}$ & $\begin{array}{l}\text { Polarisations } \\
\text { er Polarisation } \\
\text { er Widerstan } \\
\text { o verhältnism } \\
\text { esem Versuch } \\
\text { gefallen. } \\
\text { adetzlen Po } \\
\text { am vor dem L }\end{array}$ & $\begin{array}{l}\text { ersuch. } \\
\text { versuch. Die } \\
\text { war durch } \\
\text { Big wenig ver } \\
\text { war der Wide } \\
\text { trisationsversu } \\
\text { n, der Widers } \\
\text { den. }\end{array}$ & $\begin{array}{l}\text { emperatur hat } \\
\text { is Laden von } \\
\text { dert. } \\
\text { Land nach dem } \\
\text { ind bei } 1360^{\circ}\end{array}$ & $\begin{array}{l}\text { ch um } 10^{\circ} \\
0 \text { Ohm auf } \\
\text { tur um } 10^{\circ} \\
3000 \text { Ohm }\end{array}$ \\
\hline
\end{tabular}


Von Baryt ist es schon bekannt, daß derselbe elektrolytisch leitet, und die Versuche bestätigen dies; sie zeigen aber, was sehr wichtig ist, daß zwischen diesem Salz und manchem der hier untersuchten der Unterschied in der Polarisation auch quantitativ kein so bedeutender ist. Die verwendete Platte war parallel geschnitten.

Bei $1100^{\circ}$ war der Ausschlag ein ganz minimaler, auch bei $1200^{\circ}$ war der Ladestrom $0.1 \mathrm{~m} \mathrm{~A}$ und der Entladungs-

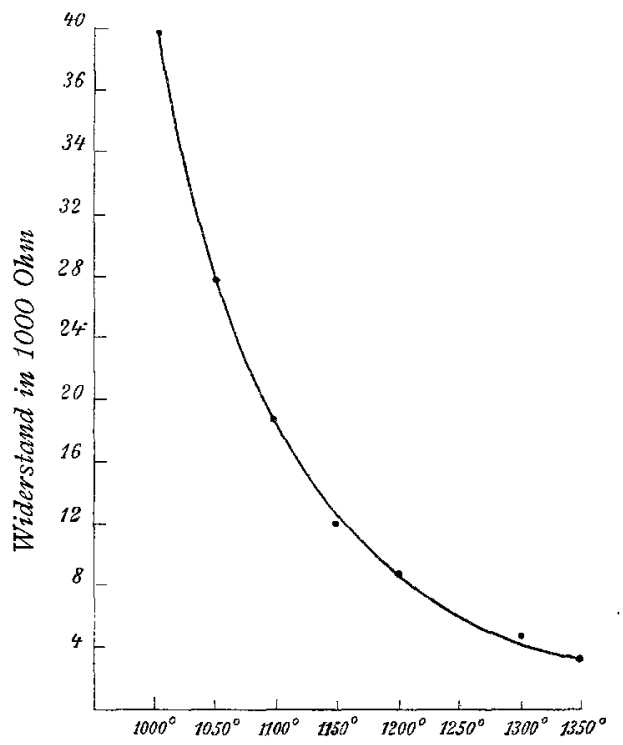

Fig. 16. Baryt.

ausschlag nur $18 \mathrm{~mm}, i=0.182 \mathrm{~m} \mathrm{~A}$; demnach verhält sich der Baryt nicht anders als die früher erwähnten Krystalle.

Erst bei $1300^{\circ}$, wo der Widerstand schon sehr gering war und durch 5 Minuten ein Ladestrom von $0.5 \mathrm{~m}$ A durchgegangen war, ergab sich ein großer Ausschlag am Spiegelgalvanometer, nämlich $56 \mathrm{~mm}$, entsprechend $i=0.59 \mathrm{~m}$ A. Doch ist hier ein bedeutender Anteil des Thermostromes inbegriffen, so daß dem Polarisationsstrom nur zirka $0.266 \mathrm{~m} A$. entsprechen, beziehungsweise eine Spannung von $1 \cdot 1 \mathrm{Volt}$.

Bei $1350^{\circ}$ wird ein Ausschlag von $96 \mathrm{~mm}$ erreicht; hier ist aber ein bedeutender Thermostrom $(65 \mathrm{~mm})$ abzuziehen, 
so daß für den Polarisationsstrom $i=0.33 \mathrm{~m}$ A oder 0.99 Volt verbleiben; möglicherweise ist aber der Anteil des Thermo-

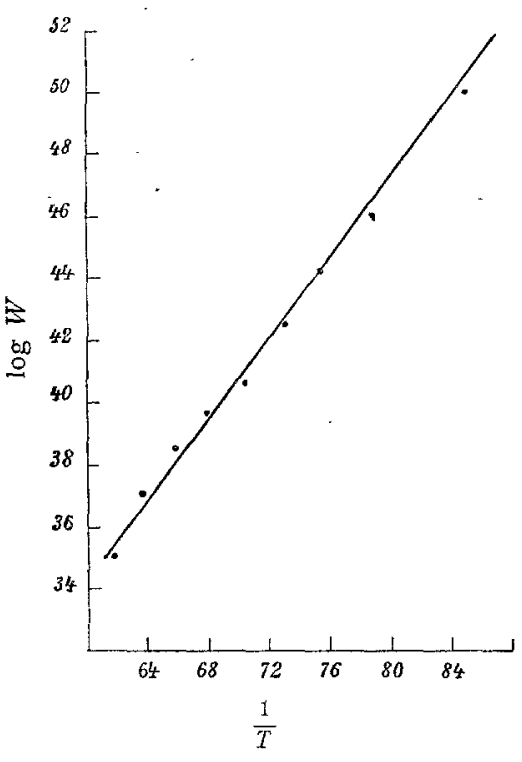

Fig. 17. Baryt. stromes doch geringer. Der ursprüngliche Ausschlag von $96 \mathrm{~mm}$ ergibt $i=0.922$ $m$ A, entsprechend zirka 3 Volt. In Wirklichkeit wäre demnach der Polarisationsstrom einer Spannung von mehr als 1 Volt entsprechend; er ist also drei- bis fünfmal höher als bei den anderen untersuchten Krystallen.

Der Vergleich des Barytes mit einigen der anderen untersuchten Krystallen zeigt nun allerdings einen weit größeren Betrag des Polarisationsstromes als bei jenen, aber immerhin ist der Unterschied kein so bedeutender, um die Annahme zu rechtfertigen, es läge nur hier elektrolytische Leitung vor, in den früheren Fällen jedoch keine.

\section{Wolframit.}

Der zur Untersuchung verwendete Wolframit stammt von Schlaggenwald; ob er vollkommen rein ist, läßt sich wegen seiner Undurchsichtigkeit nicht bestimmen. Als unzweifelhaftes Salz wäre bei Wolframit Elektrolyse und daher auch im festen Zustand elektrolytische Leitung zu erwarten; doch scheint dies nicht der Fall zu sein oder wenigstens wiegt die metallische Leitung weitaus vor. Ein Minimum in der Temperaturkurve konnte nicht gefunden werden, was jedoch nicht ausschließt, daß ein solches bei niederen Temperaturen vorhanden sein kann, wenn es auch kein stark ausgesprochenes ist.

Bei Wolframit ist schon bei ziemlich niederer Temperatur, bei $200^{\circ}$, der Widerstand verhältnismäßig unbedeutend und bei 
Elektrizitätsleitung in Krystallen.

\section{Wolframit.}

(Fig. 18.)

\begin{tabular}{|c|c|c|c|}
\hline $\begin{array}{c}\text { Temperatur } \\
\text { von } 0^{\circ} \mathrm{C} \\
\text { gemessen }\end{array}$ & $\begin{array}{c}\text { Widerstand } \\
\text { in Ohm }\end{array}$ & $\begin{array}{c}\frac{1}{T} \\
\text { in absolutem } \\
\text { MaRe }\end{array}$ & $\log W$ \\
\hline \hline $56^{\circ}$ & 11.050 & 0.00312 & 4.0434 \\
100 & 2.500 & 0.00270 & 3.3979 \\
150 & 690 & 0.00238 & 2.8389 \\
200 & 360 & 0.00213 & 2.5563 \\
300 & 110 & 0.00175 & 2.0414 \\
3501 & 67 & 0.00161 & 1.8261 \\
400 & 43.8 & 0.00149 & 1.6415 \\
5002 & 20.7 & 0.00130 & 1.3160 \\
600 & 11.7 & 0.00115 & 1.0682 \\
700 & 6.8 & 0.00103 & 0.8325 \\
780 & 4.9 & 0.00095 & 0.6902 \\
900 & 2.4 & 0.00085 & 0.3802 \\
1000 & 2.19 & 0.00079 & 0.3404 \\
1050 & 0.97 & 0.00075 & -0.0132 \\
1100 & 0.83 & 0.00073 & -0.0809 \\
1 Bei $350^{\circ}$ & wurde der erste Polarisationsversuch ausgefuhrt. \\
2 Zweiter Polarisationsversuch. & & \\
& & &
\end{tabular}

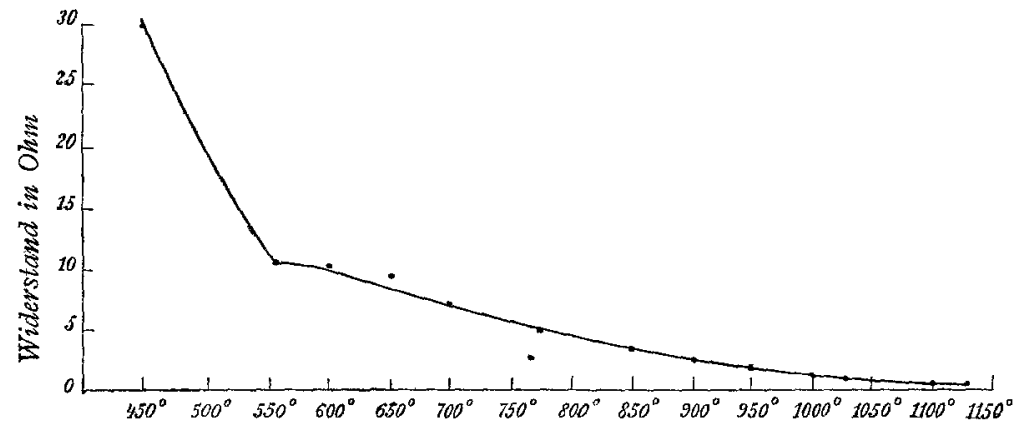

Fig. 18. Wolframit. 
$1000^{\circ}$ beträgt er nur noch zirka $1 \mathrm{Ohm}$, um dann noch weiter $z u$ fallen. Bei der Abkühlung sind die Beträge nunmehr geringere. Die zweite Erhitzung ergibt ebenfalls etwas geringere Beträge als die erste, was gewöhnlich der Fall zu sein pflegt.

Was die Polarisation anbelangt, so scheint solche hier nicht ausgeschlossen, wenn auch die Polarisationsspannung jedenfalls eine sehr geringe ist; jedenfalls sind hier Thermoströme vorwiegend.

Bei $500^{\circ}$ zeigt sich ein sehr großer Ladestrom, nämlich $200 \mathrm{~m} \mathrm{~A}$, der Ausschlag ist aber nur $13 \mathrm{~mm}$, der sofort zurückgeht.

Bei $1050^{\circ}$ ist der Ladestrom durch einen Akkumulator verursacht: $1900 \mathrm{~m}$; der Ausschlag am Galvanometer ist ziemlich groß, $28.5 \mathrm{~mm}$, geht aber sofort zurück, $i=0.606 \mathrm{~m} \mathrm{~A}$; entweder liegen Peltier'sche Ströme vor oder wir haben es mit einem sehr großen Reststrom zu tun.

Daß Wolframit metallische I.eitung hat, steht auch im Zusammenhang mit seinen optischen Eigenschaften, Undurchsichtigkeit und Metallglanz, die denen der Metalle gleichkommen. Hier wären Messungen des Schwächungskoeffizienten (vgl. p. 504) angezeigt, um die Maxwell'sche Beziehung zu prüfen.

Es ist zwar auch hier nicht ausgeschlossen, daß bei hohen Temperaturen neben der Elektronenleitung auch Ionenleitung vorhanden ist; aber erstere ist jedenfalls bei niedereren Temperaturen allein vorhanden und wir haben hier das Beispiel eines Salzes mit metailischer Leitung.

\section{Schlußfolgerungen.}

In Krystallen kann nach den vorliegenden Resultaten sowohl Ionen- wie Elektronenleitung vorkommen. In seltenen Fällen gibt die Widerstands-Temperaturkurve genügenden Aufschluß, meistens muß die Messung der Polarisation zur Entscheidung herangezogen werden, doch sind immer noch Fälle vorhanden, in welchen diese Entscheidung schwierig ist, was wohl auch damit zusammenhängt, daß häufig in Krystallen beide Arten der Leitung vorhanden sein können und bei hoher Temperatur in der Nähe des Schmelzpunktes Ionenleitung auftritt. 
Eine Verfolgung der Temperaturkurve bis in den schmelzflüssigen Zustand würde eher geeignet sein, die Frage mehr zu klären. Überblicken wir die Resultate, so können wir auf Grund der Temperatur-Widerstandskurve und der nachgewiesenen Polarisation dreierlei Kategorien von Körpern unterscheiden. Erstens Krystalle, die keine Polarisation zeigen, bei denen die Leitfähigkeit mit der Temperatur zunimmt; zu diesen gehören Rutil,Zinnstein, Chrysoberyll, vielleichtWolframit. Zweitens solche, welche bei sehr hoher Temperatur geringe Polarisation zeigen, wie Adular, Albit und drittens Krystalle, die bei höherer Temperatur eine sehr merkliche Polarisationsspannung aufweisen, wie Baryt, Saphir, Topas. Der Quarz, auf den ich zurückkomme, nimmt eine Ausnahmestellung ein. Bei allen nimmt der Widerstand mit der Temperatur ab.

Bei der zuletzt genannten Art von Krystallen sind die gemessenen Beträge der Polarisation sehr verschieden, oft nur geringere, oft merkliche. Wir können aber aus diesen Messungen nur dann einen Schluß ziehen, wenn wir die Widerstände und die Polarisationspannungen bis in den flüssigen Zustand verfolgen. Wir haben in dieser Hinsicht auch Material aus den älteren Arbeiten von Poincarré, Foussereau und namentlich von R. Lorenz, dann aus meinen Untersuchungen an Silikatschmelzen.

Dort, wo die Polarisation im flüssigen Zustande geringfügige Beträge ergibt, können im festen auch nur ganz kleine Zahlen sich ergeben, bei verhältnismäßig geringem Widerstand, was wohl mit der Ionenbeweglichkeit und auch dem "Reststrom « zusammenhängt, welche Verhältnisse nicht ganz geklärt sind. Im Gegensatz dazu ergeben die Messungen von Lorenz bei den Chloriden, Jodiden der Schwermetalle ganz außerordentlich hohe Beträge entsprechend der größeren Dissoziation und der großen Ionenbeweglichkeit im flüssigen $\mathrm{Zu}$ stande.

Ganz anders verhalten sich die Silikate. Die Polarisationsspannung beträgt in der Schmelze nur zehntel Volt. ${ }^{1}$ Es steht

1 Ich berichtige hiermit einen störenden Druckfehler in meiner Arbeit $>$ Dissoziation der Silikatschmelzen«. Sitzungsber. der Wiener Akad., 11Z, 317; es soll dort für die Polarisation des geschmolzenen Labradorit der Wert mit 
dies im Einklange mit dem ziemlich großen Widerstande im flüssigen Zustande, der wohl weniger eine Folge geringfügigen Dissoziationsgrades ist, als mit der großen Viskosität und der daraus resultierenden sehr geringen Ionenbeweglichkeit zusammenhängt.

Bei den Silikaten, von welchen früher Albit, Labradorit, Diopsid im flüssigen Zustande, Diopsid, Adular auch im festen untersucht wurden, ist infolge der großen Viskosität auch im flüssigen Zustande die Leitfähigkeit eine geringe und erst weit über dem Schmelzpunkte ist mit abnehmender Viskosität die Leitfähigkeit bedeutender, daher auch die Polarisation in der Schmelze gering und natürlich ergeben sich im festen Zustande noch geringere Beträge. Daraus läßt sich aber nicht schließen, daß es sich bei diesen Krystallen um metallische Leitung handeln muß, weil die Beträge geringer sind als bei anderen stark elektrolytisch leitenden Salzen. Daß auch in Silikatschmelzen Dissoziation vorhanden ist, läßt sich nicht bezweifeln, um so mehr als in einem Falle bei Albit bei der Ladung mit dem Straßenstrom sogar Elektrolyse auftrat, so daß die Elektroden stark angegriffen wurden; besonders die Kathode hatte sehr gelitten.

In anderen Fällen wies in solchen Schmelzen der Polarisationsstrom nur eine Spannung von 0.33 Volt auf, bei einem Widerstand von $164 \Omega$, ist also geringer als bei manchen festen Krystallen, z. B. Baryt, Saphir.

Bei Silikaten liegt also ein Fall vor, der mit den anderen nicht ganz vergleichbar ist, vielleicht ist hier der Reststrom sehr groß, jedenfalls zeigen manche Silikate sowohl im flüssigen, als auch im festen Zustande geringe Polarisation. Die Ionenbeweglichkeit ist in diesen viskosen Schmelzen gering, wie ja alle Verhältnisse der Silikatschmelzen durch ihre. Viskosität beeinflußt werden und diese in vielen Eigenschaften von anderen Salzen abweichen.

Der Widerstand im flüssigen Zustande ist immer noch ein größerer, z. B. bei Labradorit, wo er bei $1310^{\circ}$, also etwas

0.23 Volt (nicht Millivolt) eingesetzt werden, wie ja aus der Rechnung ersichtlich ist. 
über dem Schmelzpunkte noch $236 \mathrm{Ohm}$ betrug; bei Albit ist er allerdings bei $1200^{\circ}$, also über dem Schmelzpunkte geringer, nämlich $22 \cdot 71 \mathrm{Ohm}$. Es ist $z u$ beachten, daß die Leitfähigkeit des Albits trotz größerer Viskosität bedeutend größer ist, ungefähr zehnmal so groß wie die des Labradorits, wie ja bei Albit Elektrolyse im schmelzflüssigen Zustande leicht durchführbar ist. Dabei verhält sich die Leitfähigkeit des Albits zwischen $1000^{\circ}$, wo er noch fest ist, und $1250^{\circ}$, wo er flüssig ist, wie $1: 2$ und die Kurve dieses Silikats zeigt bei Übergang vom festen in den flüssigen Zustand, wenn man die graphische Darstellung nach Kohlrausch - Arrhenius wählt, eine gerade Linie. Albit dürfte sehr stark dissoziiert sein trotz großer Viskosität der Schmelze.

Bei Albit tritt Polarisation im festen wie im flüssigen Zustande auf. Bei Labradorit besteht die Kurve aus zwei Teilen, die Widerstände sind auch im flüssigen Zustande sehr groß, ${ }^{1}$ daher kann die Polarisation auch im festen Zustande nur klein sein.

Es wäre wünschenswert gewesen, die Kurve des Zinnsteines, Wolframits, Chrysoberylls bis zu dem Schmelzpunkte zu verfolgen, woran ich jedoch durch die hohen Schmelzpunkte verhindert war.

Wenn diese Körper im flüssigen Zustande elektrolytisch leiten würden, so könnte man eher zu einem Schlusse kommen, bezüglich einer wahrscheinlichen elektrolytischen Leitung auch ünterhalb des Schmelzpunktes.

Bei Magnetit würde die Möglichkeit vorliegen, daß er im flüssigen Zustande metallisch leitet, weil solche Fälle bekannt sind. Die Untersuchung wird daher in dieser Richtung zu ergänzen sein. Man müßte jedoch in einer Stickstoffatmosphäre die Versuche vornehmen, um eine Veränderung des Magneteisens zu verhindern. Nach Has s 1 in ge r würde nämlich Magnetit bei hohen Temperaturen elektrolytisch leiten.

Daß Elektronenleitung auch im flüssigen Zustande möglich ist, sehen wir an Metallen; auch metallische Leiter, wie manche Sulfide, also Salze der Schwefelwasserstoffsäure, dann Sulfo-

1 Dissoziation der Silikatschmelzen, I, p. 26. 
basen, Sulfosäuren können vielleicht im flüssigen Zustande Elektronenleitung zeigen; der Antimonit, das Antimontrisulfid, der als das Anhydrid der sulfantimonigen $\mathrm{H}_{2} \mathrm{SbS}_{2}$ betrachtet werden kann, zeigt im flüssigen Zustande nach Schilling Elektronenleitung. ${ }^{1}$ Es ist immerhin wabrscheinlich, daß solche metallische Leiter auch im flüssigen Zustande Elektronenleitung zeigen und umgekehrt.

Der am schwierigsten zu entscheidende Fall ist jedenfalls der unter I genannte, da hier vielleicht der Einwurf, daß es sich um Peltierwärme handeln kann, möglich ist; der Beweis, daß wirklich Polarisation auftritt, ist nicht in dem Maße zu erbringen, wie bei den zuletzt erwähnten. Immerhin darf der Betrag, welchen die Messung des Polarisationsstromes ergibt, nicht ganz als maßgebend angesehen werden, da wir, wenn wir diese Beträge bei den verschiedenen festen Körpern vergleichen, einen allmählichen Übergang zwischen hohen Beträgen zu sehr kleinen finden und wahrscheinlich noch häufig finden werden, wenn die vorläufig nicht große Zahl der untersuchten Stoffe sich vergrößert haben wird.

Schwierigkeiten bei der Entscheidung der Frage macht insbesondere der Quarz. Bei Platten senkrecht zur Achse wirken, wie schon früher erwähnt, die parallel zu dieser verlaufenden feinen Kanäle ${ }^{2}$, seien sie nun, wie das aus den Arbeiten von Warburg und Tegetmeyer hervorgeht, mit Natriumsilikat oder in anderen Fällen auch mit einer anderen kolloiden Lösung angefüllt, jedenfalls ist die unter $1000^{\circ}$ auftretende starke elektrolytische Leitfähigkeit eine sekundäre und erst bei höherer Temperatur tritt die eigentliche Leitfähigkeit des Quarzes auf.

Wir sehen große Verschiedenheit bei den untersuchten Quarzen, aber mit Ausnahme der Quarzplatten parallel zur Achse (p. 524), zeigte sich eine auffallend große Leitfähigkeit, die als seikundäre $z u$ deuten ist. In einem Falle erfolgte durch

$1 \mathrm{Königsberger,} \mathrm{Z.f.} \mathrm{Elektroch.,} \mathrm{15,} 100$.

2 Über die merkwürdige Verteilung eines beigemengten Farbstoffes im Rauchquarz gibt die Figur 5 in meinem Werke »Das Radium und die Farben Aufschluß (p. 121). 
die Ladung mit dem Straßenstrom Elektrolyse und Bildung eines Metalles, wohl Natrium, da gerade etwas unter dem Siedepunkt dieses Metalles $780^{\circ}$ plötzlich eine Erhöhung des Widerstandes eintrat und dann nach dem Verschwinden dieses Metalles die normale geringe Leitfähigkeit des Quarzes sich zeigte, die dann erst bei weiterer Erhitzung zunahm.

Was nun die Größenordnung der Polarisationsspannung anbelangt, so sind die quantitativen Unterschiede, z. B. zwischen Baryt und Adular, große; ob daraus der Schluß gestattet ist, daß bei letzterem keine elektrolytische Leitfähigkeit vorliegt, ist doch zu bezweifeln, in anderen Fällen ist der Unterschied weit geringer, z. B. zwischen Baryt und Saphir. Bei Baryt als schwefelsaurem Salz ist im vorneherein eine andere Größenordnung zu erwarten als bei Silikaten; die wässerige Lösung von Schwefelsäure ist ja sehr stark leitend, die von Kieselsäure nur äußerst wenig, es dürften daher Sulfate und Silikate sich auch darin stark unterscheiden. Es ist aber nicht nötig, daraus den Schluß zu ziehen, daß es sich um zwei verschiedene Arten der Leitfähigkeit handelt.

Wir können die Krystalle in folgende Gruppen einteilen:

$A$. solche, bei denen bei gewöhnlicher Temperatur und wohl bei allen Temperaturen Elektronenleitung ohne gleichzeitige Ionenleitung auftritt. In diese Gruppe gehören: Bleiglanz, Eisenglanz, Antimonglanz, Titaneisen, Magnetit und Pyrit.

Aber auch hier ist Eisenglanz, der bei gewöhnlicher Temperatur guter metallischer Leiter ist, doch nicht ganz mit Pyrit zusammen $z u$ werfen, da derselbe nach den Untersuchungen von J. Königs berger bei niedrigeren Temperaturen größeren Widerstand hat als bei $20^{\circ}$.

Wichtig ist die Kurve für Titaneisen (Ilmenit), welche Königsberger bis $700^{\circ}$ verfolgt hat; diese Kurve ist der Form nach der des Magnetits ähnlich, die der Genannte ebenfalls von $100^{\circ}$ bis $200^{\circ}$ studierte. Bei Ilmenit wäre ein Verfolgen über $800^{\circ}$ notwendig, um ein etwaiges Ansteigen der Kurve ausfindig zu machen. Die beiden Verbindungen zeigen über $200^{\circ}$ respektive $600^{\circ}$ nur noch sehr geringen Widerstand. Polarisation konnte bei beiden, obgleich bei llmenit ein salzartiger 
Charakter der Verbindung wahrscheinlich ist, nicht konstatiert werden. Königsberger glaubt, daß für alle Verbindungen mit Elektronenleitung der Minimalwert des Widerstandes etwa zwischen 0.0003 und $0.025 \Omega$ pro Quadratzentimeter liegt.

$B$. Es gibt dann Krystalle, welche bei gewöhnlicher Temperatur Isolatoren sind, dann bei wenig bedeutender Temperaturerhöhung metallisch leiten; zu ihnen gehören Zinkblende, dann Molybdänglanz, Pyrit, Fahlerz und Antimonglanz.

C. Dann haben wir Körper wie Zinnstein und Chrysoberyll, bei denen Polarisation nicht sicher konstatiert wurde, die jedenfalls teilweise metallische Leitung zeigen, aber vielleicht doch bei höherer Temperatur elektrolytisch leiten, ein gleichzeitiges Vorkommen beider Arten der Leitung ist dann denkbar.

Wie aus den Versuchen bei Zinnstein (Cassiterit) hervorgeht, zeigt derselbe metallische Leitung, welche bei geringer Temperaturerhöhung auftritt; bei Zimmertemperatur ist der Zinnstein ein Isolator, bei $900^{\circ}$ überaus stark leitend. Es wäre wünschenswert, die Temperaturkurve bis zu niederen Temperaturen zu verfolgen, obgleich nach dem ganzen Verlauf eine Vergrößerung des Widerstandes bei solchen Stoffen zu erwarten steht.

Polarisation wird bei Zinnstein nicht beobachtet. Jedenfalls müßte aber untersucht werden, wie sich die Schmelze verhält und der feste Körper etwas unterhalb des Schmelzpunktes, denn es ist möglich, daß dann beide Arten der Leitung eintreten könnten.

Bei Rutil scheinen ähnliche Verhältnisse vorzuliegen wie bei Zinnstein; ferner gehört hieher der Chrysoberyll, bei dem elektrolytische Leitung trotz geringer Polarisation möglich wäre.

Von Quarz, $\mathrm{SiO}_{2}$, verhalten sich Bergkrystall und Rauchquarz nicht ganz gleich.

Die beiden Rauchquarze, die untersucht wurden, stammen zwar nicht von demselben Stücke, aber von demselben Fundorte. Alle untersuchten Rauchquarze, wie auch Bergkrystallplatten waren senkrecht zur optischen Achse geschnitten worden. Nun wissen wir aus den Untersuchungen von Warburg und Tegetmeyer, daß diese Platten eine weit größere 
Leitfähigkeit zeigen, als solche, welche parallel der optischen Achse geschnitten sind.

Die mitunter bei verhältnismäßig niederen Temperaturen auftretende Leitfähigkeit des Quarzes ist also wohl durch Beimengungen hervorgebracht und die Ladung der Zelle ergibt hier starke Veränderungen. Erst bei hoher Temperatur tritt die weit geringere eigene Leitfähigkeit des Quarzes ein, die erst bei sehr hoher Temperatur eine größere wird; damit verbunden ist dann eine wenn auch geringe Polarisation. Es ist also nicht ausgeschlossen, daß Quarz bei solchen hohen Temperaturen elektrolytisch leite.

Was die optischen Eigenschaften des Quarzes anbelangt, so zeigt er nach Drude wie viele Salze selektive Absorption im Ultrarot. Königsberger führt an, daß Substanzen mit Elektronenleitung keine Eigenschwingung im Ultrarot haben, was aber dann für Quarz nicht zutrifft. Was die zugunsten der Elektronenleitung angeführte kontinuierliche Emission der Oxyde wie Zirkonoxyd, Ceroxyd anbelangt, so schloß Nernst nicht auf metallische Leitung, vergl. p. 502.

Kontinuierliche Emission zeigt in demselben Maße wie Quarz auch Porzellan und Quarzglas, für welche wohl zumeist Ionenleitung angenommen wird.

$D$. Endlich gibt es Körper, die bei gewöhnlicher Temperatur Isolatoren sind, die aber bei hohen Temperaturen gute elektrolytische Leiter sind und dabei merkliche Polarisation zeigen, die allerdings quantitativ verschiedene Werte haben kann.

Große Beträge der Polarisation zeigen die von Lorenz untersuchten Chloride, Jodide, die auch im festen Zustande weit unter dem Schmelzpunkte stark leiten. Weiter ist das Bariumsulfat gewiß ein elektrolytischer Leiter bei hohen Temperaturen.

Ferner gehört nach Haber und Tolloczko hierher das Chlorbarium.

Nach Untersuchungen von Haber und Tolloczko zeigt Chlorbarium weit unter seinem Schmelzpunkte Elektrolyse

1 Z. f. physische Chemie, 41, 407 (1904). 
bei $400^{\circ}$ und es weist bei $600^{\circ}$ Polarisationspannung von 1. 9 Volt auf. Auch für Chlorsilber, Chlornatrium, Glas und Porzellan ist die elektrolytische Leitung durch F. Haber nachgewiesen; es sind erstere allerdings in Wasser lösliche Körper. Königsberger fand bei Bariumsulfat bei $800^{\circ}$ einen Widerstand von $20.000 \Omega$ und eine Polarisation gegen Goldelektroden von 1.09 Volt. Wir haben hier trotz der Schwerlöslichkeit im Wasser Elektrolyse; es ist also die Löslichkeit nicht immer maßgebend.

Die Silikate, Saphir, vielleicht auch Quarz haben bei höheren Temperaturen elektrolytische Leitfähigkeit und schon im festen Zustande zeigen sie Polarisation, die allerdings oft sehr schwach ist, was bei Körpern zutrifft, die auch im schmelzflüssigen Zustande schwachen Gegenstrom zeigen; manchmal wie bei Albit, Topas, Saphir ist aber die Polarisation sehr merklich.

Für den festen Zustand ist die metallische Leitung also nicht charakteristisch, viele Salze wie Oxyde zeigen Ionenleitung, welche man vom flüssigen Zustand in den festen allmählich verfolgen kann. Der manchmal eintretende Sprung oder Knick in der Temperaturkurve ist im Zusammenhange mit dem Übergange aus dem amorphflüssigen Zustand in den regelmäßig angeordneten Krystallzustand; wenn ein Körper glasig erstarrt, tritt kein Knick ein. Wahrscheinlich hängt die Änderung hauptsächlich mit der geringeren Ionenbeweglichkeit zusammen, wobei natürlich auch die Möglichkeit einer Änderung des Dissoziationsgrades beim Übergang vom flüssigen in den krystallisierten Zustand in Erwägung zu ziehen ist.

Es liegt aber kein Grund vor anzunehmen, daß im festen Zustande Ionenleitung und Dissoziation ausgeschlossen wären; es hängt das hauptsächlich von dem Verhalten im schmelzflüssigen Zustande ab; stark dissoziierte Schmelzflüsse zeigen auch nach dem Festwerden noch Dissoziation.

Es wird sich die Notwendigkeit ergeben, gerade in denjenigen Fällen, die noch unentschieden sind, wie Zinnstein und Quarz, die Schmelzflüsse zu untersuchen.

Wir können uns im Einklange mit den optischen Eigenschaften und daher mit der elektromagnetischen Lichtheorie zweierlei krystallisierte Körper denken: solche, welche sich wie 
die Metalle verhalten, sowohl optisch wie in bezug auf die Leitfähigkeit und durchsichtige, nicht metallische Stoffe, die bei gewöhnlichen Temperaturen nichtleiten (auch schlechte Wärmeleiter sind), aber bei hohen Temperaturen elektrolytisch leiten, endlich dürfte es Krystalle geben, die zweierlei Arten von Leitung gleichzeitig aufweisen können. Die meisten Sauerstoffsalze sind Elektrolyte, doch kann es wohl solche geben, wie Wolframit, die metallisch leiten, wie es andrerseits auch Oxyde, wie Saphir gibt, die elektrolytisch leiten.

Leitfähigkeit und Polymorphie. Die Löslichkeit polymorpher Arten ist verschieden, daher auch ihr Dissoziationsgrad. Polymorphe Arten bilden sich wie z. B. Kalkspat und Aragonit aus verschiedenen konzentrierten Lösungen mit verschiedenem Ionengehalt. Die Polymorphie hängt also wahrscheinlich mit der Leitfähigkeit zusammen. Die bei höherer Temperatur stabile Form hat die größere Leitfähigkeit. ${ }^{1}$ Bei erhöhter Temperatur und Ionenbeweglichkeit kann das Raumgitter, in dem auch die Kationen anfangs festgelegt waren, sich verändern und diese eine andere Lage einnehmen, welche dann größeré Wanderungen erlaubt. Welches die Ursache der Veränderung bei einer bestimmten Temperatur ist, bleibt wie bisher unklar. Man könnte an einen Valenzwechsel denken, an ein Komplexerwerden der Ionen oder an das Umgekehrte, an Dissoziation und Depolymerisation der Moleküle.

Möglicherweise sind es dieselben Vorgänge, welche größere Ionen- oder Elektronenbeweglichkeit verursachen und auch die Krystallform ändern, jedenfalls wird ein Teil der Ionen, welche vorher festgelegt waren, in diesen Salzen zum Teil frei.

Damit wird auch eine Volumsveränderung eintreten und zwar meistens Vermehrung. Die Raumgitteränderung geht Hand in Hand mit dem Beweglichwerden vorher fester Ionen.

Fester Zustand und Leitfähigkeit. Bei festen Elektrolyten wandern die Kationen.

Bei Isolatoren wird man sich zunächst Kationen wie Anionen festgelegt denken, und zwar im Raumgitter. Es ist

1 Vgl. die Arbeit von Beyeringk und die von Königsberger, Jahrbuch der Radioaktivität, 4, 177. 
dies wahrscheinlicher als die Hypothese von Groth und Barlow, wonach die Atome selbst im Raumgitter verteilt sind, Nur bei Metallen könnte man sich das Raumgitter mit positiven Atomresten besetzt denken, während das negative Elektron frei sich bewegen und Leitfähigkeit erzeugen kann.

Jene Hypothese, wonach die verschiedenen Atome einer Verbindung das Raumgitter besetzt haben, ist schon deswegen unwahrscheinlich, weil im flüssigen Zustande eine Verbindung nur in Ionen und in undissoziierte Moleküle zerfällt, nicht aber in die Atome, daher man annehmen müßte, daß beim Übergang in den festen Zustand ein Zerfall in die Atome eintreten müßte, was sehr unwahrscheinlich ist. ${ }^{1}$

Für die Theorie des festen Zustandes wird sich immerhin ergeben, daß die Ionen, d. h. wenigstens die Anionen im Krystallgitter festgelegt sind, beziehungsweise nur kleine Schwingungen um die Schwerpunkte des Raumgitters ausführen, daher keine Leitung stattfindet. Die meisten Krystalle sind daher bei gewöhnlicher Temperatur Nichtleiter. Leiter sind die Metalle und die Krystalle mit metallischen Eigenschaften; bei diesen wird die Leitfähigkeit durch negative Elektronen hervorgebracht sein, der positive Atomrest liegt im Raumgitter, aber die Möglichkeit, daß auch bei ihnen Ionen vorkommen, wäre nicht ausgeschlossen. Bei hoher Temperatur kann bei größeren Schwingungsamplituden eine geringe Ionenbeweglichkeit auftreten, die in der Nähe des Schmelzpunktes stark zunimmt, der Körper wird allmählich plastisch, das Kation wandert. Auch bei sonst metallisch leitenden kann bei Temperaturerhöhung eine allerdings im Verhältnis zur Elektronenleitung geringe Ionenleitung dann eintreten; der Dissoziationsgrad dieser Körper ist aber auch im flüssigen Zustande weit geringer.

1 Dissoziation der Silikatschmelzen, p. 35. 